\title{
Variability and Trends of Global Atmospheric Frontal Activity and Links with Large-Scale Modes of Variability
}

\author{
IRINA RUDEVA \\ School of Earth Sciences, University of Melbourne, Melbourne, Victoria, Australia, and P. P. Shirshov Institute \\ of Oceanology, Russian Academy of Sciences, Moscow, Russia \\ IAN SIMMONDS \\ School of Earth Sciences, University of Melbourne, Melbourne, Victoria, Australia
}

(Manuscript received 27 June 2014, in final form 5 January 2015)

\begin{abstract}
Presented here is a global analysis of frontal activity variability derived from ERA-Interim data over the 34-yr period of January 1979-March 2013 using a state-of-the-art frontal tracking scheme. In DecemberFebruary over that epoch, there is a northward shift of frontal activity in the Pacific in the Northern Hemisphere $(\mathrm{NH})$. In the Southern Hemisphere (SH), the largest trends are identified in the austral summer and are manifested by a southward shift of frontal activity over the Southern Ocean.

Variability of frontal behavior is found to be closely related to the main modes of atmospheric circulation, such as the North Atlantic Oscillation (NAO) for the Atlantic-European sector in the NH and the southern annular mode (SAM) in the middle and high latitudes of the SH. A signal associated with El Niño and hence emanating from the tropics is also apparent in the behavior of frontal systems over the Pacific by a reduction in the number of fronts in the middle South Pacific and intensification of frontal activity in high and low latitudes throughout the year. It is shown in general that the associations of the large-scale modes with frontal variability are much stronger than with cyclones. This indicates that the quantification of the behavior of fronts is an important component of understanding the climate system. At the very high latitudes, it is also shown here that, in the recent years of rapid sea ice reduction in the Arctic, there have been fewer summer fronts observed over the Canadian Arctic.
\end{abstract}

\section{Introduction}

Day-to-day weather and climate in the middle and high latitudes are strongly affected by extratropical cyclones. Over recent decades there have been many publications investigating the characteristics and variability of atmospheric cyclones and anticyclones for understanding climate variability and change in the extratropics. However, observed weather does not always have a simple relationship with particular characteristics of atmospheric cyclones (e.g., their intensity or deepening rate). For example, in June 2007 windstorm Uriah brought gale force winds to the United Kingdom and caused severe flooding with many areas receiving more than 1 month of rainfall in a single day, yet its

Corresponding author address: Irina Rudeva, School of Earth Sciences, University of Melbourne, Melbourne VIC 3010, Australia. E-mail: irina.rudeva@unimelb.edu.au central pressure only dropped to $980 \mathrm{hPa}$ and hence could be considered as a synoptic system of moderate intensity. Thus, considering only the properties of an extratropical cyclone in the vicinity of an extreme event is not sufficient for the understanding of such events and the climatological community is devoting more attention to the quantitative diagnosis of atmospheric fronts that are associated more directly with precipitation, dramatic changes in temperature and wind (direction and speed), and extreme events.

A product of this increased interest for automated frontal identification is the investigation of Berry et al. (2011). They used ERA-40 data to compile a global climatology of atmospheric fronts based on the structure of the thermal frontal parameter (TFP), a measure first proposed by Renard and Clarke (1965). This method allows for identification of cold and warm fronts, as well as quasi-stationary fronts in the areas of high contrasts of potential temperature (e.g., in the coastal regions). 
Simmonds et al. (2012) assembled a climatology of Southern Hemisphere (SH) mobile fronts using a "wind shift" approach to define fronts. The motivation for introducing a novel technique of objective frontal identification was that they found that temperature-based approaches often produce quite complex patterns, which might be associated, for example, with the diurnal cycle over continents or with coastal areas and thus need a posteriori masking. By contrast, they demonstrated that an algorithm based on the meridional component of the wind reveals patterns that had a significantly more identifiable structure and bore similarity with those that would have been identified as a front by a synoptician. Schemm et al. (2015) undertook a comparison of these two approaches to frontal identification [temperature based (TH) and wind based (WND)] and found that the WND algorithm tends to identify cold fronts that are meridionally elongated and are typically shorter than corresponding $\mathrm{TH}$ fronts. Consistent with this, they showed that the frequency of $\mathrm{TH}$ fronts is about twice that of the WND frontal systems, which corresponds well with the absence of warm fronts and shorter cold fronts in the WND outputs. They found that the WND method provides very robust results in frontal identification.

Objectively identified fronts have been recently used in a number of analyses on the relationship between fronts and precipitation. Hope et al. (2014) compared the skills of six frontal identification methods (including a manual one) as associated with rain over southwest Western Australia. In their study, the WND algorithm showed the strongest correlation with rainfall in this particular area. Catto et al. (2012) used a TH method to relate global precipitation to atmospheric fronts. They showed that $90 \%$ of rainfall in the major storm track regions is associated with atmospheric fronts. Using the same frontal identification method, Catto and Pfahl (2013) found that $75 \%$ of precipitation extremes were associated with fronts in the midlatitudes. They also showed that a large proportion of extreme precipitation events occur in the presence of both a cyclone and a front but "remote" fronts (i.e., fronts that are at some point along their length associated with cyclones but parts of fronts that are associated with precipitation are located outside the cyclone area) are responsible for many of the "front only" events. Papritz et al. (2014) developed a novel approach to attribute precipitation to either cyclones or fronts and showed that over the Southern Ocean between $60 \%$ and $90 \%$ of the total intense precipitation is due to these synoptic systems. Cyclones were found to be the dominant cause of intense precipitation around Antarctica and in the midlatitudes of the Atlantic, while in the midlatitudes of the south Indian Ocean and the eastern Atlantic fronts bring most of the intense precipitation. They also showed that variations in cyclone and frontal activity explain a large portion of the variability of freshwater fluxes and intense precipitation in the $\mathrm{SH}$ extratropics. The authors pointed to the value of using observed frontal trends and relationship with indices of atmospheric circulation for understanding precipitation behavior in the middle latitudes. Their study underpins the importance of the analysis of frontal variability in more detail than has been presented in the literature until now.

In this paper, we focus on the global analysis of variability of frontal activity and associated frontal characteristics in winter and summer using the Interim ECMWF Re-Analysis (ERA-Interim) from January 1979 to March 2013. We estimate the trends in frontal frequency during that period and also examine the relationships between frontal activity and various modes of atmospheric circulation [e.g., the North Atlantic Oscillation (NAO), the southern annular mode (SAM), El Niño], which are known to be closely associated with anomalies in synoptic activity and, thus, are expected to affect (or be affected by) the frontal activity. The impact of the atmospheric circulation modes on the leading modes of frontal variability, identified with empirical orthogonal function (EOF) analysis, is also investigated. Furthermore, variability of frontal activity is contrasted with the behavior of extratropical cyclones. Our analysis indicates that a comprehensive analysis of frontal activity is a key component for understanding climate variability.

\section{Data and methods}

In the analysis of frontal variability, we make use of ERA-Interim (Dee et al. 2011). This reanalysis belongs to the so-called modern-era reanalyses: that is, it makes use of extensive satellite observations. Hodges et al. (2011) and Tilinina et al. (2013) intercompared cyclone activity in four modern-era reanalyses, including ERAInterim, and concluded that spatial climatologies of the cyclone counts were relatively consistent across them. This gives us confidence that at least cyclones and probably fronts are well represented in their outputs. However, other atmospheric parameters, particularly those related to the hydrological cycle, are less successfully reproduced in reanalyses, especially over the Southern Ocean (Bromwich et al. 2011). Nicolas and Bromwich (2011) concluded that the ERA-Interim provides the most reliable trend estimates and shows fewest artificial jumps in latent heat flux and precipitation. As climatological frontal variability is the focus of this paper, we limited ourselves to the ERAInterim dataset and suggest that good representation of hydrological cycle may be an indication of the physical 
consistency within the dataset. The sets used here are sea level pressure (SLP) and 10-m wind at 6-hourly intervals on a global $1.5^{\circ}$ latitude-longitude grid for the period from January 1979 to March 2013.

For frontal identification, the objective method of Simmonds et al. (2012) was applied, which focuses on the identification of mobile fronts. This is an Eulerian scheme that requires that between sequential 6-hourly analyses the wind shifts from northwest (southwest) quadrant to the southwest (northwest) quadrant in the $\mathrm{SH}$ [Northern Hemisphere (NH)] and that the magnitude of the change in the meridional wind component exceeds $2 \mathrm{~m} \mathrm{~s}^{-1}$ [for more detailed discussion on the parameter settings, see Schemm et al. (2015)]. An obvious advantage of this method is its simplicity, which makes frontal identification easy to interpret and very time efficient. Moreover, in contrast to TH methods that often show artificial fronts in the subtropical regions or high latitudes (e.g., in the areas of large thermal and/or moisture gradients; Catto et al. 2012), the WND method shows more robust results.

In addition to the identification of fronts the WND approach includes the estimation of frontal intensity $(I)$. This parameter incorporates both frontal length and the average increase in the wind speed along the front, so that it reflects an integrated effect of the front. Simmonds et al. (2012) defined $I$ as

$$
I=\frac{\Delta \theta \times 111}{1000} \frac{6}{\Delta t} \sum_{i=1}^{N}\left|v_{i}(t+\Delta t)-v_{i}(t)\right|,
$$

where $\Delta \theta$ is the distance between frontal points along the meridian in degrees (here $1.5^{\circ}$ ), $\Delta t$ is the time step (here $6 \mathrm{~h}$ ), $v_{i}$ is the meridional wind component at the $i$ th frontal point, and $N$ is the number of such points that compose the front. The number 111 in the numerator pertains to the number of kilometers covered by $1^{\circ}$ of latitude. The numerical value of the units of $I$ is $\mathrm{m} \mathrm{s}^{-1}$ $(1000 \mathrm{~km})$. For mapping purposes frontal density is shown for all frontal points, whereas $I$ was attributed to the center of gravity of a front defined as the average longitude and latitude of each front (for details, see Simmonds et al. 2012).

In addition to frontal identification we performed cyclone identification using the University of Melbourne cyclone tracking scheme (Simmonds and Keay 2002; Lim and Simmonds 2007). The algorithm objectively identifies cyclones at 6-hourly intervals based on the structure of SLP fields. This scheme has been used in a range of analyses of cyclone activity in both hemispheres and its results are in good agreement with other methods used for cyclone identification and tracking (e.g., Pinto et al. 2005; Raible et al. 2008; Simmonds et al.
2008; Neu et al. 2013). Following Neu et al. (2013), the minimum lifetime of a cyclone was set to five 6-hourly time steps (i.e., 1 day). Cyclone frequency (or cyclone center density) was estimated as the number of cyclone centers per unit area, as opposed to the number of cyclone tracks passing the unit area.

For the analysis of interannual variability of synoptic features, a range of indices that describe the changes in the atmospheric circulation regimes was used. For the $\mathrm{NH}$, we explored associations with the NAO, the northern annular mode (NAM), and the North Pacific pattern (NP). The Hurrell principal component-based NAO index was downloaded online (from https:// climatedataguide.ucar.edu/climate-data/hurrell-northatlantic-oscillation-nao-index-pc-based). The advantage of a PC-based index is that it can be used to measure the NAO throughout the year, tracking the seasonal movements of the Icelandic low and Azores high, as opposed to a station-based index (Hurrell 1995). The NAM index was downloaded online (from https://climatedataguide. ucar.edu/climate-data/hurrell-wintertime-slp-based-northernannular-mode-nam-index) and defined as the first EOF of $\mathrm{NH}\left(20^{\circ}-90^{\circ} \mathrm{N}\right)$ SLP data in the cold season [DecemberMarch (DJFM)]. The NP index for November-March (NDFJM) has been obtained online (from https:// climatedataguide.ucar.edu/climate-data/north-pacific-npindex-trenberth-and-hurrell-monthly-and-winter) and is the area-weighted SLP over the region $30^{\circ}-65^{\circ} \mathrm{N}, 160^{\circ} \mathrm{E}-140^{\circ} \mathrm{W}$.

For the SAM index, we use the normalized difference in the zonal-mean SLP between $40^{\circ}$ and $65^{\circ} \mathrm{S}$ (Gong and Wang 1999). The Niño-3.4 index, provided by the NOAA/Climate Prediction Center, was calculated as the sea surface temperature (SST) anomalies (relative to the period $1971-2000)$ for the area $5^{\circ} \mathrm{N}-5^{\circ} \mathrm{S}, 120^{\circ}-170^{\circ} \mathrm{W}$.

The statistical significance of the trends and correlations has been assessed at the $90 \%$ confidence level (unless specified otherwise) and only significant patterns are discussed in the paper. Moreover, for each map a field significance test similar to that of Livezey and Chen (1983) was performed to aid in the assessment of the statistical significance of the results. This approach takes into account the finiteness and interdependence of individual significance tests. A Monte Carlo strategy is used to find the minimum number of points that show significant correlation (or trend) at $90 \%$ level for each field and then this number is compared with the actual number of significant correlations. If the latter is smaller, then the correlations are deemed to be not significant (i.e., the field has failed the test), and such fields were excluded from the analysis (hence all the maps shown here have passed the field significance test). The test was performed between $20^{\circ}$ and $80^{\circ}$ of latitude in each hemisphere over the areas where frontal (or 
(a) Frontal frequency, DJF 1979-2012

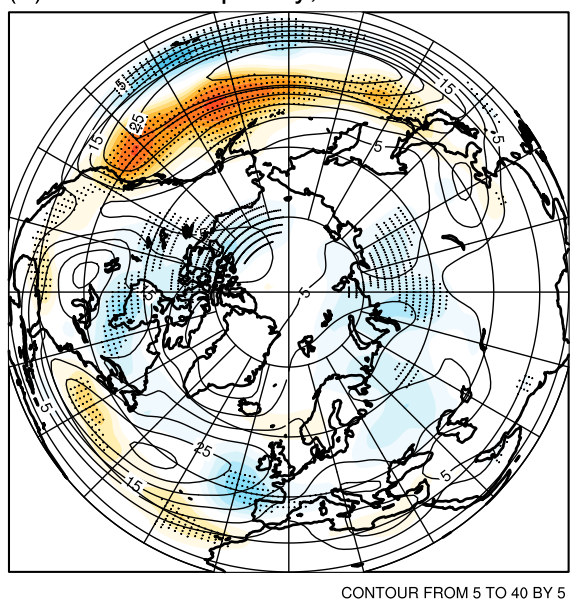

(c) Cyclone frequency, DJF 1979-2012

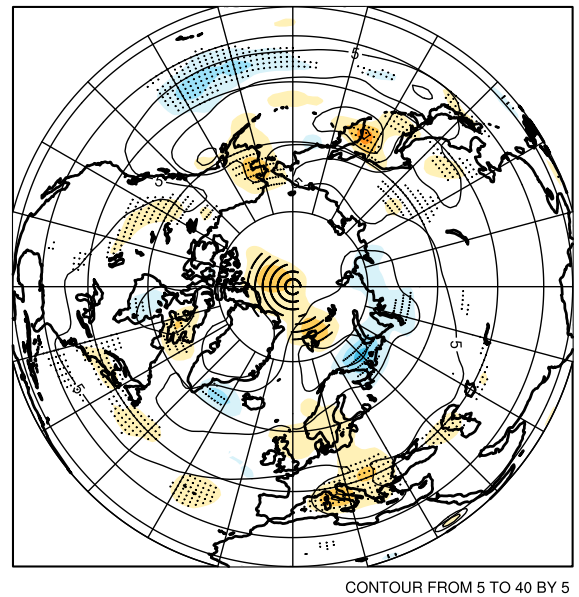

(b) Frontal frequency, JJA 1979-2012
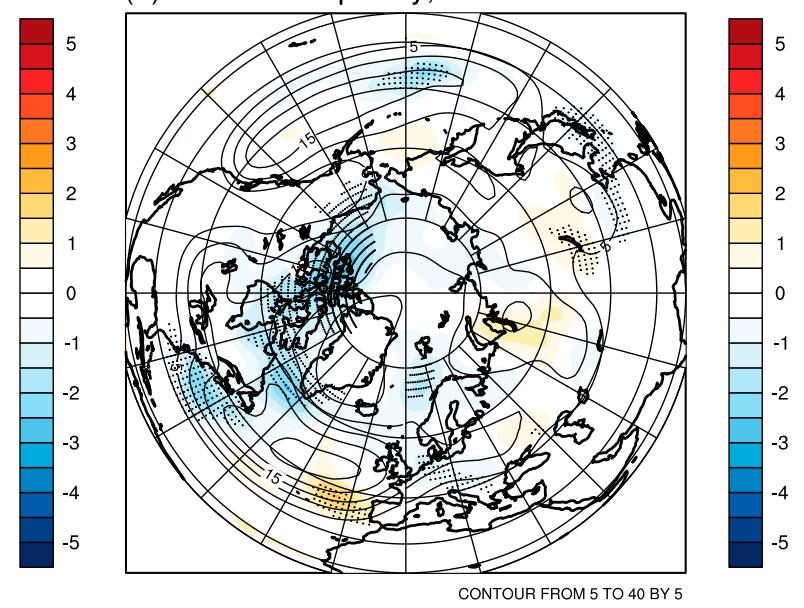

(d) Cyclone frequency, JJA 1979-2012

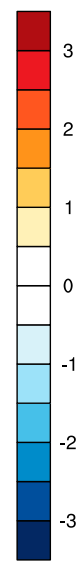

FIG. 1. (a) DJF and (b) JJA decadal linear trends (color) and averaged frontal frequency (contour lines) in the NH. The units $U$ for frontal frequency are counts of frontal points $\times 10^{-2}$ per analysis per a circle of $2^{\circ}$ of latitude, and the trends are in $U$ decade $^{-1}$. Stippling shows trends significant at $90 \%$ level. (c),(d) As in (a),(b), but for cyclone frequencies.

cyclone) frequency was over 0.01 system within a circle of radius of $2^{\circ}$ of latitude (which corresponds to an area of approximately $155 \times 10^{3} \mathrm{~km}^{2}$; for convenience, we refer to this as the unit area). This is because synoptic systems are not homogeneously distributed over the globe, and thus points that had very small number of systems but still showed a significant correlation were excluded from the analysis. Taking this rigorous approach ensures that only robust features of interannual variability are analyzed in our study.

Additionally, the dominant modes of frontal and cyclone variability were identified by EOF analysis between $20^{\circ}$ and $90^{\circ}$ of latitude in each hemisphere. We also considered the sampling errors, which can lead to unstable estimations of the EOF vectors (North et al. 1982).

\section{Results}

\section{a. Linear trends in frontal frequency}

Figure 1 shows averaged frontal and cyclone density and observed trends in the NH. The highest climatological frequencies are seen in the belt $35^{\circ}-50^{\circ} \mathrm{N}$ throughout the year, particularly over the oceans, being shifted slightly poleward during warmer seasons. In DJF (December-February; Fig. 1a), frontal frequencies reach their maximum of about 0.3 fronts in the middle of the oceans. Linear trends over the Pacific and Atlantic show opposite tendencies: in the Pacific the maximum of frontal activity shifts northward to the south of the Aleutian Islands (up to $3.5 \times 10^{-2}$ fronts per decade), while in the Atlantic small positive trends are observed to the south of the area of main frontal activity. Cyclone 
(a) Frontal frequency, DJF 1979-2012

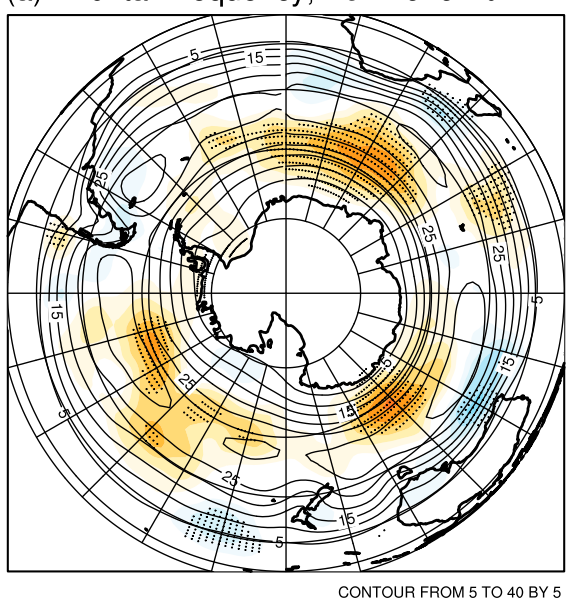

(b) Frontal intensity, DJF 1979-2012

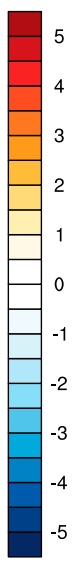

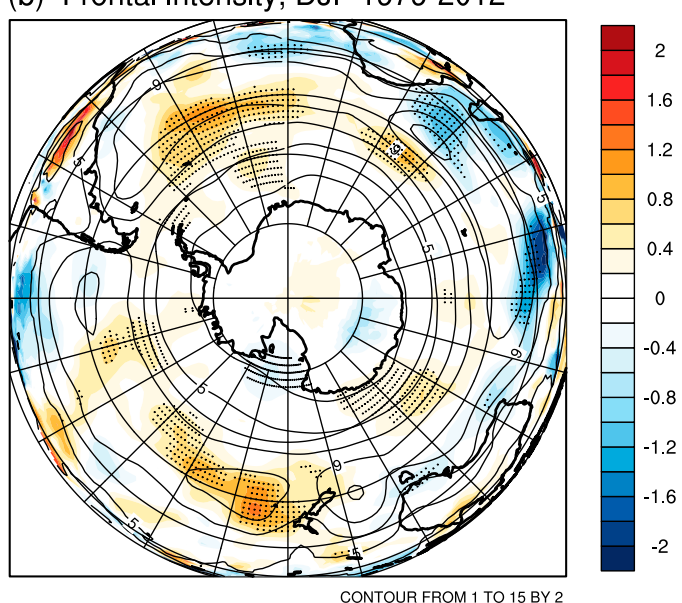

FIG. 2. (a) DJF (color) decadal linear trends and (contour lines) averaged frontal frequency in the SH. The units $U$ for frontal frequency are counts of frontal points $\times 10^{-2}$ per analysis per a circle of $2^{\circ}$ of latitude, and the trends are in $U$ decade $^{-1}$. Stippling shows trends significant at $90 \%$ level. (b) As in (a), but for the frontal intensity. The units for frontal intensity are $\mathrm{m} \mathrm{s}^{-1}(1000 \mathrm{~km})$.

activity in the North Pacific demonstrates similar behavior with patterns being shifted poleward compared to the frontal trends. This is explained by alignment of fronts relative to the cyclone centers: fronts, especially cold ones, are usually elongated toward the equator from the cyclone center. Consistent with the trends in frontal frequency, there is an increase in the number of cyclones in the southern part of the North Atlantic. The negative trend in cyclone activity in the central North Pacific is in agreement with the results in Tilinina et al. (2013) derived from the MERRA reanalysis. However, in the south of the North Atlantic, Tilinina et al. (2013) showed a reduction in the number of cyclones. Over the continents, negative trends in DJF frontal frequencies are observed to the north and northeast of North America, to the west of Europe, and in Siberia (up to $3 \times$ $10^{-2}$ fronts per decade). Trends in cyclone activity are rather small and generally of positive sign. Interestingly, in the Mediterranean there is no significant change in frontal activity while the number of cyclones has increased $\left(1.5 \times 10^{-2}\right.$ cyclones per decade $)$.

Summer [June-August (JJA)] frontal frequencies (Fig. 1b) are lower than in the cold season, particularly in the North Pacific, where the number of fronts drops by a factor of 2 ( 0.15 fronts). JJA trends are characterized by weakening of frontal activity in the $\mathrm{NH}$ except for small regions east of Portugal $\left(2 \times 10^{-2}\right.$ fronts per decade) and around Lake Baikal. The largest area of negative JJA trends in the frontal activity (up to $3 \times 10^{-2}$ fronts per decade) is located off the east coast of North America and over the Canadian Arctic Archipelago (CAA), which has hosted rapid sea ice loss in recent years (Simmonds and Keay 2009). Despite weakening of JJA frontal activity, cyclone activity is slightly strengthening over the NH. However, while changes in both frontal and cyclone activity are statistically significant, they are not very strong. As trends are not very pronounced, the opposite tendencies in frontal and cyclone activities might be explained by the change of some other characteristics of the synoptic systems. For example, Tilinina et al. (2013) showed that the number of deep cyclones has been consistently decreasing over the 1989-2010 period, which might cause a reduction in the number of fronts as well as a decrease in the averaged frontal length. It is worth noting that, in agreement with Tilinina et al. (2013), cyclone frequency trends show different signs across the CAA, while Hakkinen et al. (2008) found an increase in the storminess in the Arctic when analyzing the magnitude of the surface wind stress over a 57-yr period (19502006) and Simmonds and Keay (2002) found a similar positive trend in the Atlantic sector of the Arctic. It is salutary to note that Simmonds et al. (2008) have shown that the nature of the trends in Arctic cyclone counts depends to a significant extent on the period analyzed and the reanalysis set employed. We mention that, overall, the $\mathrm{NH}$ trends in $I$ were not significant (not shown).

The SH trends in synoptic activity were only statistically significant for summer (DJF) frontal frequency and I. The highest frontal frequencies (Fig. 2a) are seen in a belt between $40^{\circ}$ and $60^{\circ} \mathrm{S}$. Within this belt, there are regional oceanic maxima east of Patagonia, southeast of southern Africa, and southwest of Australia, where the 


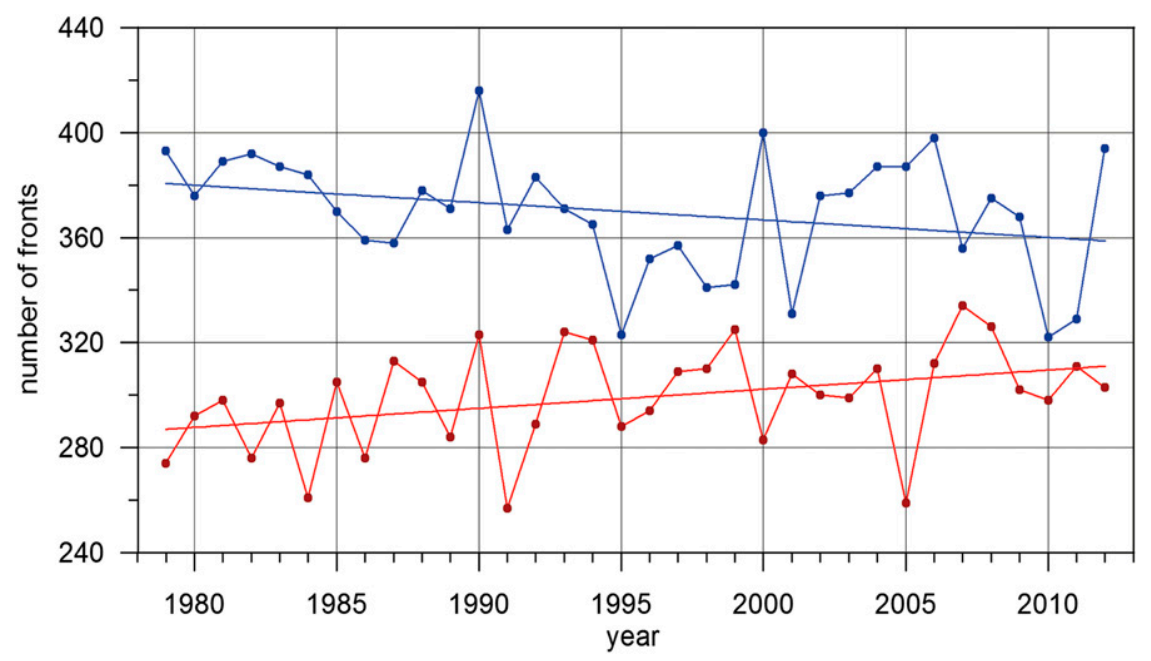

FIG. 3. DJF time series for the number of fronts in the $\mathrm{SH}$ in a belt of $30^{\circ}-50^{\circ} \mathrm{S}$ (blue line) and $50^{\circ}-70^{\circ} \mathrm{S}$ (red line).

number of fronts exceeds 0.35 per unit area per analysis. DJF positive trends of the frontal activity are seen in a belt between $50^{\circ}$ and $70^{\circ} \mathrm{S}$, representing a shift of atmospheric fronts to the high latitudes, which corresponds well with major shifts in the SH circulation since the mid-1970s (Pezza et al. 2007, 2008; Chen and Held 2007; Archer and Caldeira 2008) and is consistent with the results of Solman and Orlanski (2014), who found that frontal activity, defined in terms of the temperature gradient multiplied by the relative vorticity, has shifted poleward during 1962-2001. Within the belt of maximum changes in frontal activity, there are regional maxima to the south of Africa and Australia and in the southeast South Pacific (over $3 \times 10^{-2}$ fronts per decade). In lower latitudes, there are a few areas of decreasing frontal activity in DJF. The observed DJF trends (significant at 95\% level) are also manifested in the time series of the DJF number of fronts in two belts, $30^{\circ}-50^{\circ} \mathrm{S}$ and $50^{\circ}-70^{\circ} \mathrm{S}$ (Fig. 3), while the combined number of fronts between $30^{\circ}$ and $70^{\circ} \mathrm{S}$ (not shown) does not show a significant trend. There is a marked increase in the frontal frequency in high latitudes since $1979(\sim 5$ fronts per decade per the belt $\left.50^{\circ}-70^{\circ} \mathrm{S}\right)$ with a corresponding reduction in frontal activity in the midlatitude belt $\left(\sim 7\right.$ fronts per decade per the belt $\left.30^{\circ}-50^{\circ} \mathrm{S}\right)$.

In addition to the information on frontal frequency, we also show the DJF climatological means and the linear trends in frontal intensity $I$ in the SH. This parameter (Fig. 2b) shows its maximum in the belt between $35^{\circ}$ and $45^{\circ} \mathrm{S}$, with the highest values in the west Indian Ocean and weaker maxima in the Atlantic and western Pacific. Interestingly, the location of maximum $I$ exhibits very little interseasonal variation and reaches its maximum of $15 \mathrm{~m} \mathrm{~s}^{-1}(1000 \mathrm{~km})$ in JJA (as will be seen in
Fig. 7c). However, $\mathrm{SH}$ trends in the winter frontal intensity are not statistically significant. The summer $I$ trend pattern is characterized by intensification in the South Pacific in a belt stretching from New Zealand to the Drake Passage and then spiraling around Antarctica. In the subtropics of the Indian Ocean, in the eastern subtropical parts of the Pacific and Atlantic Oceans, and over the Ross Sea, trends of $I$ are negative.

Overall, observed trends in the frontal frequency are the most pronounced during winter in the $\mathrm{NH}$ (particularly the shift of frontal activity in the Pacific) and in summer in the SH (manifested by increasing number of fronts in the high latitudes), which agrees well with the seasonality of changes in the extratropical circulation: whereas the trends in the $\mathrm{SH}$ hemisphere peak during the summer and autumn seasons, the trends in the $\mathrm{NH}$ troposphere peak during the midwinter months from January to March (Thompson et al. 2000; Thompson and Solomon 2002). Another noteworthy feature of frontal variability is the negative trend in frontal and cyclone frequency over the CAA in summer, over the period for which the sea ice has shown a particularly strong reduction. This is consistent with the study by Screen et al. (2011), who demonstrated that during the sea ice loss years the summer cyclone activity on the Canadian side of the Arctic is reduced.

\section{b. Correlation with atmospheric circulation modes}

In this section, we explore the links between the variability in frontal frequency and some of the key hemispheric atmospheric circulation patterns via temporal correlation analysis of the seasonal averages.

Figure 4 shows the $\mathrm{NH}$ correlations with the NAO index. The NAO is known to exert a dominant influence 
(a) Fronts vs NAO, DJF

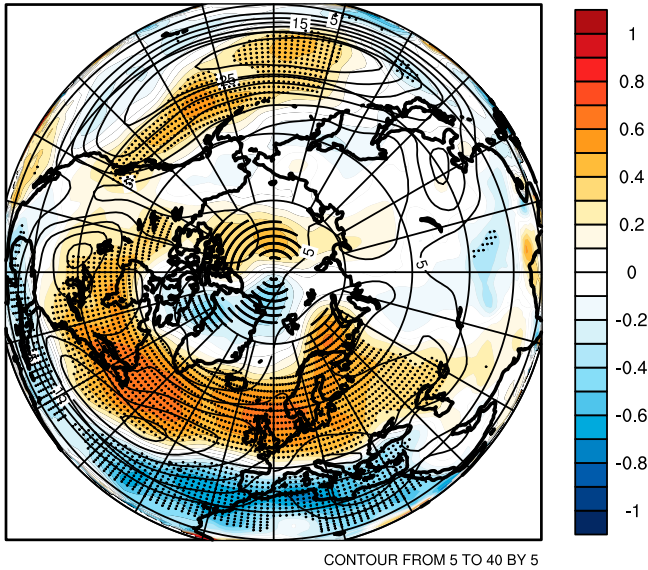

(c) Cyclones vs NAO, DJF

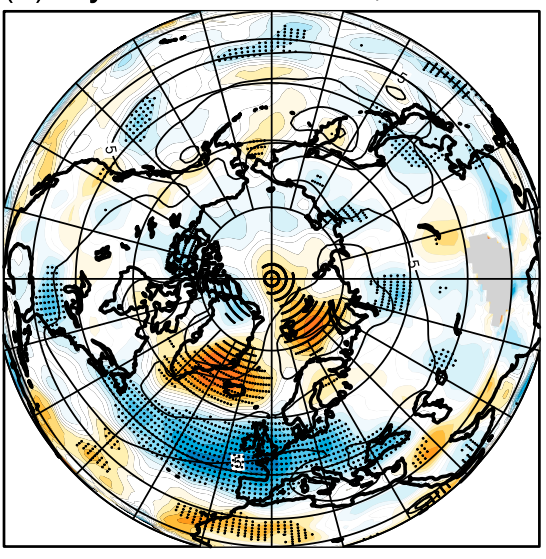

CONTOUR FROM 5 TO $30 \mathrm{BY} 5$

(e) FI vs NAO, DJF
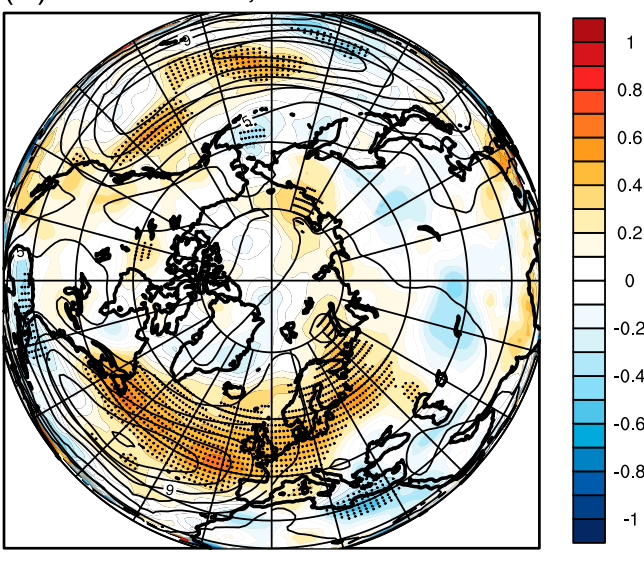

(b) Fronts vs NAO, JJA

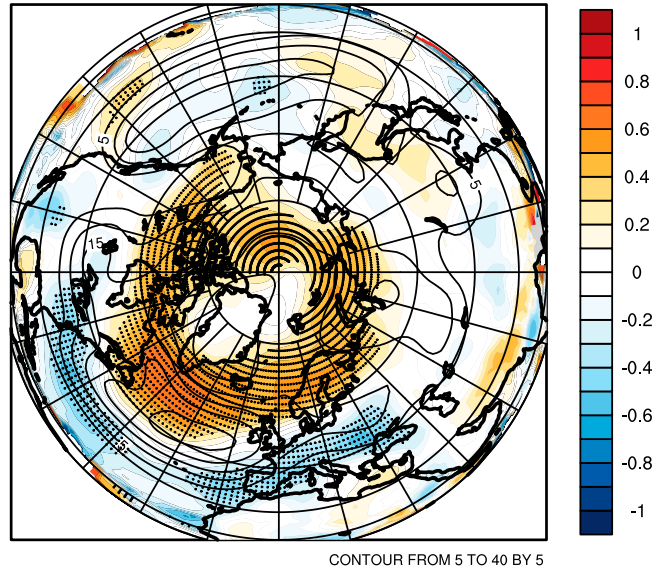

(d) Cyclones vs NAO, JJA

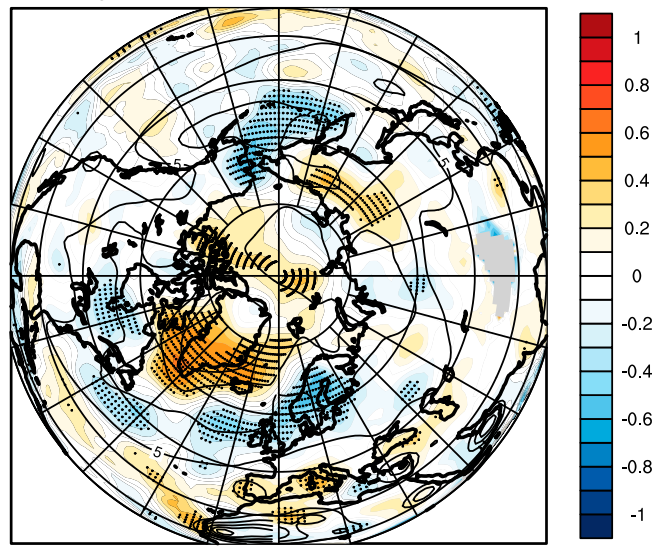

CONTOUR FROM 5 TO 30 BY 5

(f) FI vs NAO, JJA

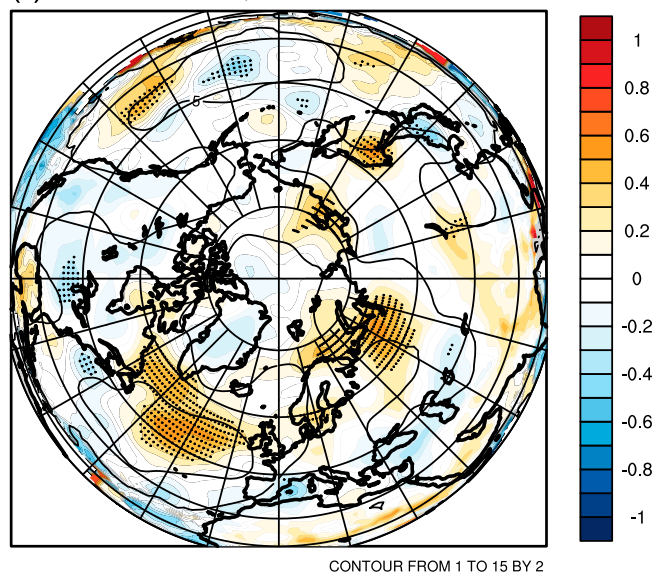

FIG. 4. (a) Correlation coefficient (color) between frontal frequency and the NAO index in (left) DJF and (right) JJA for the NH. Contour lines represent averaged frontal frequency. The units are the number of frontal points $\times 10^{-2}$ per analysis per unit area. Stippling shows correlation coefficients significant at $90 \%$ level. (b),(c) As in (a), but for cyclone frequency and frontal intensity. The units for the averaged frontal intensity are $\mathrm{m} \mathrm{s}^{-1}(1000 \mathrm{~km})$. 
on wintertime temperatures across much of the $\mathrm{NH}$ (Hurrell and Deser 2009). It also affects the Atlantic storm track, North Atlantic SST, stratospheric circulation, Arctic sea ice, and evaporation and precipitation over the Atlantic, as well as the adjacent continents (e.g., Deser et al. 2000, 2003; Comiso 2003; Cohen and Barlow 2005; Hurrell and Deser 2009). Given its central role in the $\mathrm{NH}$ weather and climate variability, it is insightful to quantify a relationship between the NAO and synoptic system characteristics.

In DJF (Fig. 4a) significant positive correlations of frontal frequency with the NAO are seen in a belt starting in North America from $35^{\circ}$ to $60^{\circ} \mathrm{N}$ and stretching across the North Atlantic to Europe, where it lies to the north of $40^{\circ} \mathrm{N}$. The maximum of correlation coefficient $(r>0.7)$ is found to the east of Newfoundland and over the United Kingdom. In the Pacific, positive correlations are also found in the midlatitudes, but are much smaller than those found in the Atlantic. In the Arctic, the correlation pattern assumes the form of a dipole with positive values on the Pacific side of the Arctic and negative values on its Atlantic side. A wide belt of negative correlations extends though the subtropical North Atlantic from the Gulf of Mexico to the Mediterranean and North Africa. Additionally, we show here correlation between the cyclone frequency and the NAO (Fig. 4c). The area of significant correlations for cyclones is noticeably smaller than for the fronts and tends to be shifted to the north: in the extratropics, positive correlations are effectively confined to the region to the east of Greenland and the Barents Sea and negative correlation coefficients are seen in the west of the North Atlantic and cover most of Europe. Figure 4e reveals positive correlations between frontal intensity and the NAO from Newfoundland to the northwest of Europe, in the midlatitude North Pacific, and a small area of negative links in the Mediterranean.

In summer (Fig. 4b), the correlation in the Atlantic is very high, reaching 0.7 to the south of Greenland. Positive correlations cover nearly all the high latitudes to the north of $60^{\circ} \mathrm{N}$. Only over and to the north of Greenland does the correlation diminish and become not statistically significant, but there are very few fronts found in this region. Negative correlations with the NAO are seen mainly in the southern parts of the North Atlantic and over Europe. Similar to the case for DJF, cyclones demonstrate smaller regions of significant correlation that are shifted poleward with $r$ not exceeding 0.5 (Fig. 4d). The frontal intensity correlation pattern resembles the frontal frequency behavior but is much weaker, so that noticeable areas of significant correlation are only seen in the middle of the North Atlantic and in the northwest of Russia.
The NAO is closely related to another mode of atmospheric circulation in NH: namely, the NAM [or the Arctic Oscillation (AO)]. Thompson and Wallace (1998) argued that the NAO is, in fact, only a regional manifestation of a hemispheric-wide AO. Positive values of the NAM are associated with lower than normal SLP over the Arctic. The main difference between the NAM and NAO is larger-amplitude anomalies over the North Pacific of the same sign as those over the Atlantic (see Fig. 8 in Hurrell and Deser 2009). The correlation of NAM with frontal frequency for DJFM is shown in Fig. 5a (in accord with the NAM index the frontal frequency was calculated for the extended winter). This pattern resembles the correlation with the NAO in the Atlantic-European sector; however, the relationship is weaker. The main difference is in the Asia-Pacific sector, where the NAM shows positive correlations with frontal frequencies with the center over the East Siberian Sea. In the northwest Pacific, the correlation is also positive and changes sign at about $40^{\circ} \mathrm{N}$. In the Arctic, negative correlation is seen to the north of Fram Strait. The correlation with cyclones in the AtlanticEuropean sector resembles the frontal pattern but is shifted to the north (Fig. 5b). In contrast to the fronts, over the East Siberian Sea cyclones are negatively correlated with the NAM. The frontal intensity is positively correlated with the NAM over the North Atlantic (Fig. 5c) with $r$ reaching 0.6, and it is therefore somewhat higher than the correlation between $I$ and the NAO.

Another large-scale mode of atmospheric circulation variability in the $\mathrm{NH}$ is the Pacific-North American teleconnection pattern (PNA), which represents variations in the waviness of the atmospheric flow in the western half hemisphere. Surprisingly, even the DJF correlations of frontal activity with the PNA index show no extended areas of statistical significance. Given this weak association of PNA with frontal frequency in the Pacific and North America, we considered the relationship with the NP index (Fig. 6a), which has received much less attention in the literature. The NP index is the area-weighted SLP over the central part of the midlatitude North Pacific (Trenberth and Hurrell 1994) and reflects the intensity of the Aleutian low. There is found a much stronger relationship between frontal activity and the NP index than that revealed with the PNA (we note, however, that correlations with cyclone frequency and $I$ fail to achieve significance for the NP index). Positive correlation with frontal frequency in NDJFM (the season for which this index is defined) is found in the Gulf of Alaska and then circles the NH across the Atlantic storm track to the Arctic along the Russian Arctic coastline. Negative correlations are seen over the central 
(a) Fronts vs NAM, DJFM

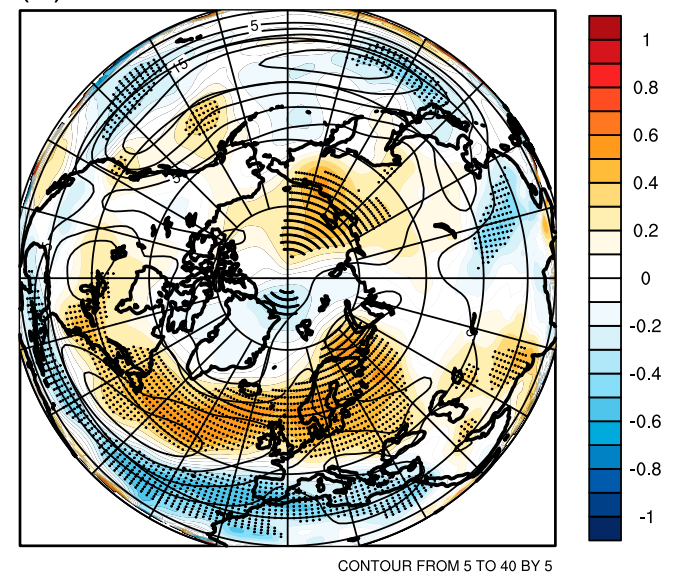

(b) Cyclones vs NAM, DJFM

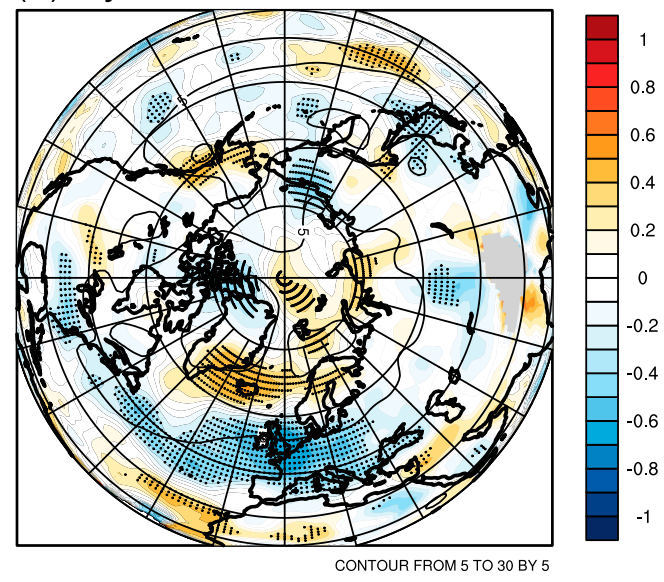

(c) FI vs NAM, DJFM

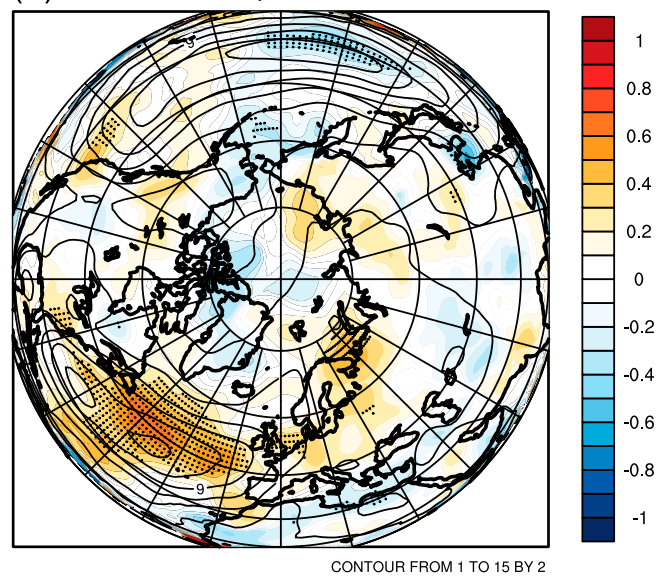

FIG. 5. (a) Correlation coefficient (color) between frontal frequency and the NAM index in DJF and for the $\mathrm{NH}$. Contour lines represent averaged frontal frequency. The units are the number of frontal points $\times 10^{-2}$ per analysis per unit area. Stippling shows correlation coefficients significant at $90 \%$ level. (b and c) As in (a) but for cyclone frequency and frontal intensity. The units for the averaged frontal intensity are $\mathrm{m} \mathrm{s}^{-1}(1000 \mathrm{~km})$.

North Pacific and subtropical North Atlantic. Overall, the spatial extent of the significant correlations is much smaller than what we saw for the NAO.

El Niño-Southern Oscillation (ENSO) is another mode of atmospheric circulation that is known to have a large global impact. Halpert and Ropelewski (1992) demonstrated an extratropical response to ENSO in the North America and Japan. During a warm episode (El Niño) winter, midlatitude low pressure systems tend to be more vigorous than normal in the region of the eastern North Pacific. These systems pump warm air into western Canada, Alaska, and the extreme northern portion of the contiguous United States. Storms also tend to be more active in the Gulf of Mexico and along the southeast coast of the United States, resulting in wetter than normal conditions in that region (Climate Prediction Center 2014). Correlation analysis of DJF frontal activity reveals an increased number of fronts in the North Pacific, Gulf of Mexico, and subtropical North Atlantic during El Niño (Fig. 6b). At the same time, the frontal frequency decreases significantly in a belt

extending from northwestern North America to the east of the United States and the western North Atlantic. This result is in good agreement with the climate impact of ENSO discussed above: that is, increasing frontal activity along the intensified Pacific jet stream causes warm air advection to the northwest of North America and wetter conditions at the border of the United States and Mexico. The correlations between the ENSO and cyclone frequency are generally weaker than with the fronts and are shifted poleward.

In the $\mathrm{SH}$, the counterpart of the NAM is the SAM (Simmonds and King 2004). The SLP pattern associated with the SAM is found throughout the year and in its positive phase has a large low pressure anomaly centered on the high southern latitudes and a ring of high pressure anomalies in the midlatitudes. By the geostrophic relation, this is associated with stronger and more poleward westerlies centered around $55^{\circ} \mathrm{S}$ when the SAM index is high. We suggest that the changing position of the westerly wind belt influences the strength and position of cold fronts and midlatitude storm 
(a) Fronts vs NP, NDJFM

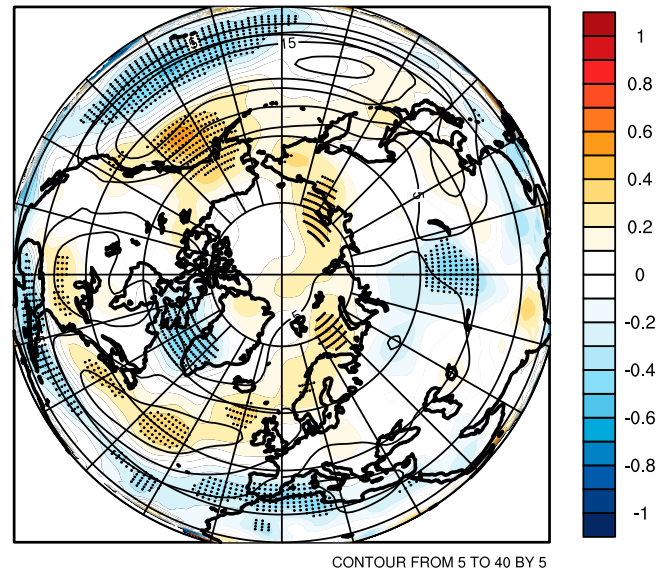

FIG. 6. (a) Correlation coefficient (color) between frontal frequency and the NP index in DJF and for the NH. Contour lines represent averaged frontal frequency. The units are the number of frontal points $\times 10^{-2}$ per analysis per unit area. Stippling shows correlation coefficients significant at $90 \%$ level. (b) As in (a), but for the ENSO. (c) As in (b), but for cyclone frequency. (b) Fronts vs ENSO, DJF

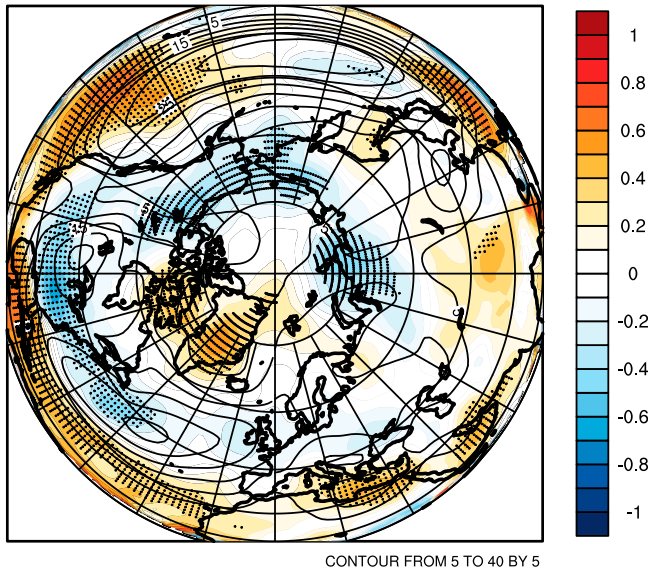

(c) Cyclones vs ENSO, DJF

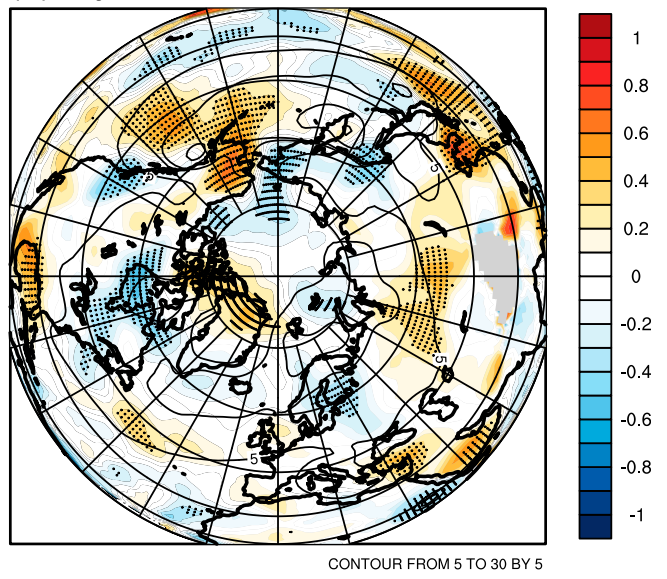

SAM and, similar to other indices, the area of positive and negative correlation is shifted poleward compared to the frontal activity: a belt of increased cyclone activity during a positive SAM is located to the south of $60^{\circ} \mathrm{S}$, while between $45^{\circ}$ and $60^{\circ} \mathrm{S}$ the number of cyclones reduces (Fig. 7c). The strongest correlation with cyclone activity $(r>0.7)$ is seen in the Indian Ocean sector of the $\mathrm{SH}$. The area between $45^{\circ}$ and $60^{\circ} \mathrm{S}$, being negatively correlated with the SAM for the cyclone frequency, demonstrates a significant positive correlation for the frontal intensity (Fig. 7e). Thus, even under reduced cyclone numbers, the midlatitudes of the $\mathrm{SH}$ experience an increased synoptic activity in case of a positive SAM event in DJF (which might lead to, e.g., increased precipitation). In winter (Fig. 7b), the area of positive correlation of frontal activity with the SAM shifts farther north in the Pacific and Indian Oceans. At the same time, in the Indian Ocean north of $45^{\circ} \mathrm{S}$ the correlation with the SAM falls to zero. In the central South Pacific and in the midlatitude South Atlantic the number of fronts decreases during positive SAM, whereas in the 
(a) Fronts vs SAM, DJF

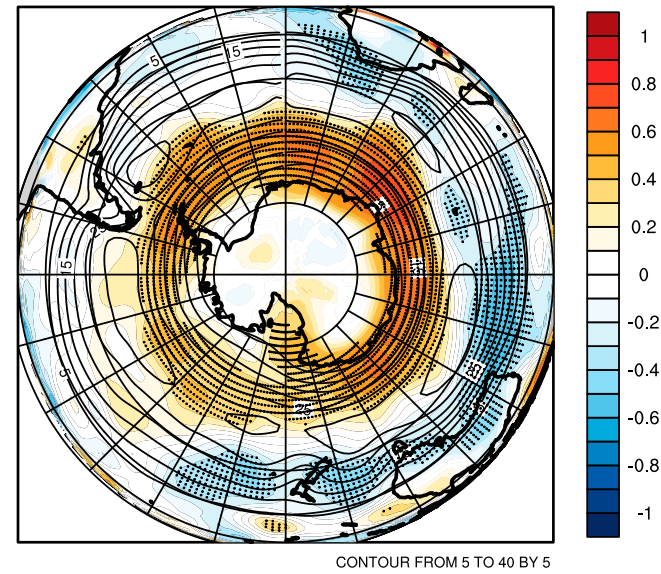

(c) Cyclones vs SAM, DJF

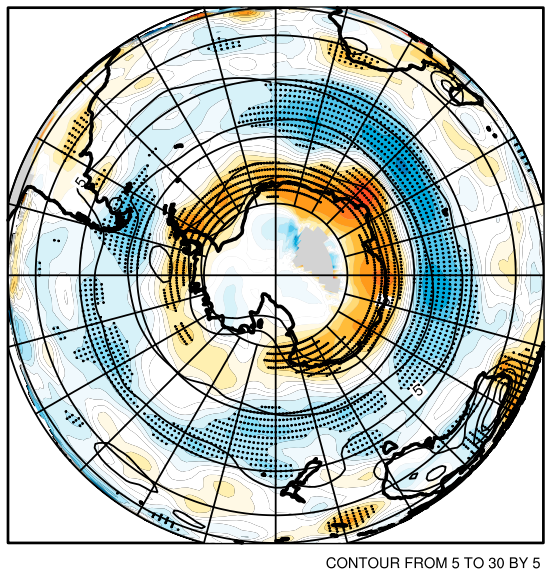

(e) FI vs SAM, DJF

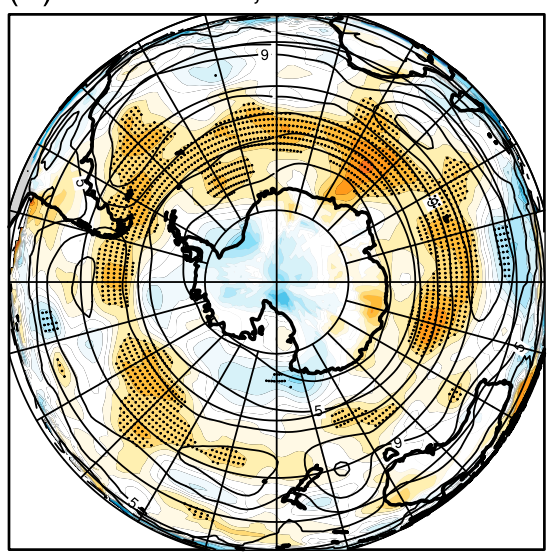

CONTOUR FROM 1 TO 15 BY 2 (b) Fronts vs SAM, JJA

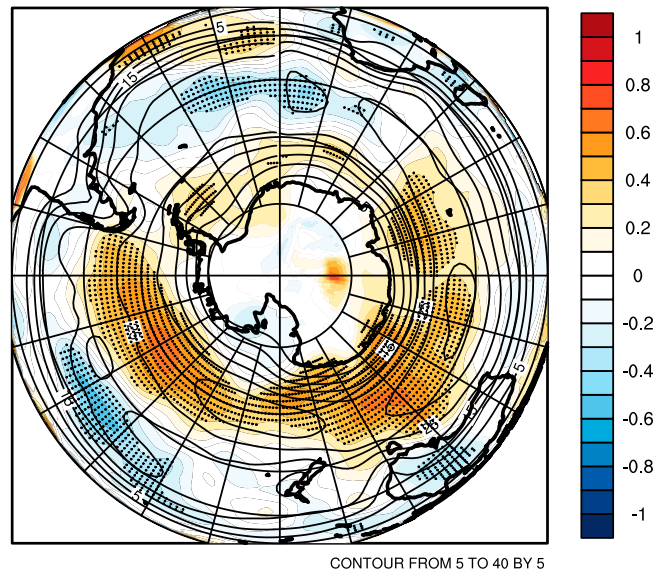

(d) Cyclones vs SAM, JJA

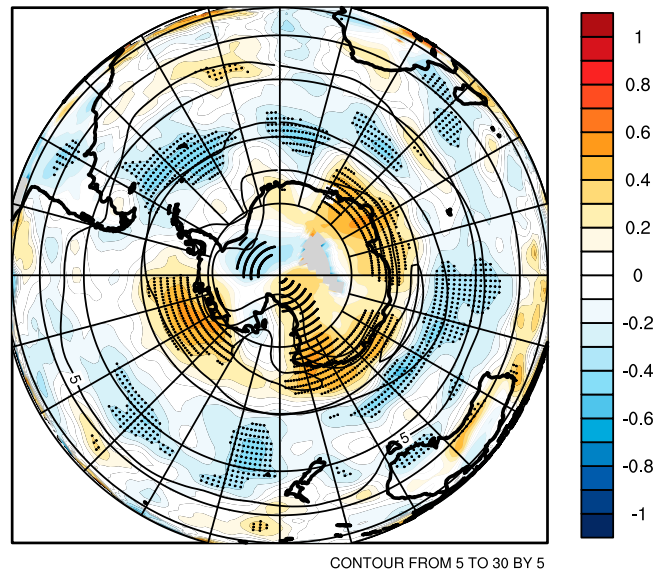

(f) FI vs SAM, JJA

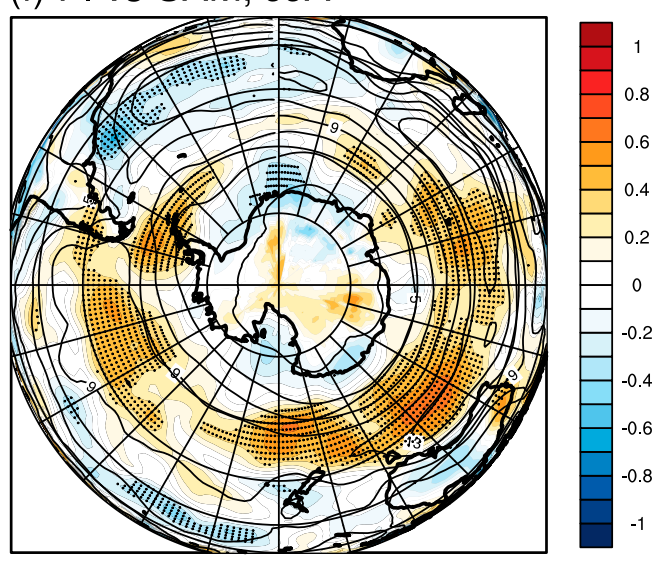

CONTOUR FROM 1 TO 15 BY 2

FIG. 7. As in Fig. 4, but for the SAM index in the SH.

subtropics of the South Atlantic frontal frequency increases in the same conditions. For the cyclone frequency the JJA correlation pattern keeps the circular structure seen in DJF; however, the most intense positive correlations are now shifted to the Pacific and
Australian sector ( $r$ up to 0.5 ). Frontal intensity increases between $30^{\circ}$ and $60^{\circ} \mathrm{S}$ in the middle Indian Ocean and to the south of Australia during the positive SAM. This area then stretches eastward to South America with a small poleward displacement. 
(a) Fronts vs ENSO, DJF

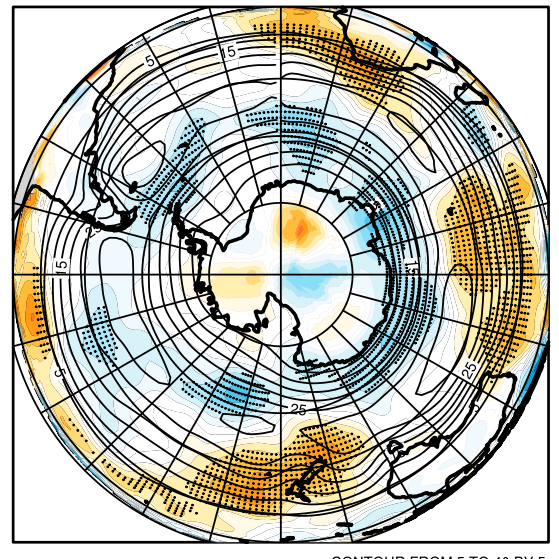

CONTOUR FROM 5 TO 40 BY

(c) Cyclones vs ENSO, DJF

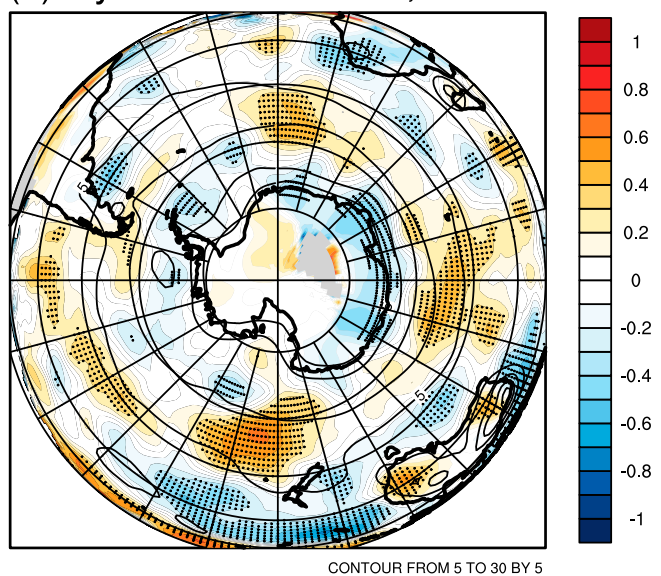

(d) FI vs ENSO, DJF

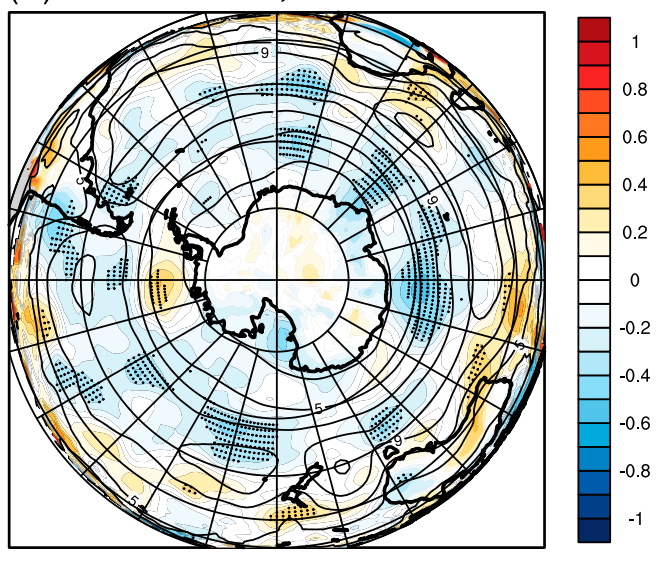

(b) Fronts vs ENSO, JJA

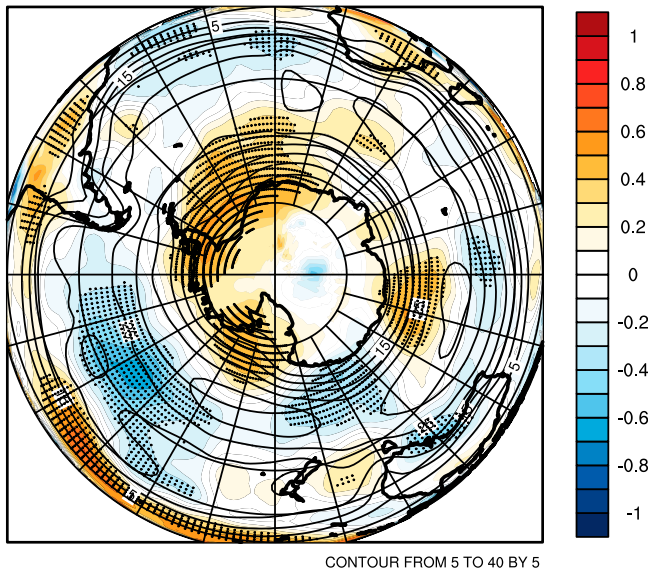

(e) FI vs ENSO, JJA

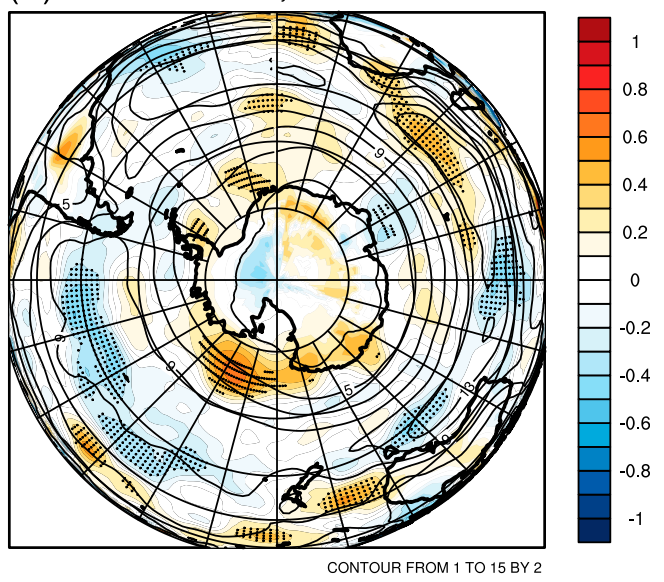

FIG. 8. (a)-(c) As in Figs. 4a-c and (d),(e) as in Figs. 4e,f, but for the ENSO 3.4 index in the SH.

Another mode of atmospheric circulation that has been already discussed in relation to the $\mathrm{NH}$ and is known to have a large impact on the SH is ENSO. El Niño-induced changes to the $\mathrm{SH}$ circulation are linked to the position and magnitude of the subtropical jet stream (STJ) and subpolar jet stream (SPJ; Trenberth et al. 1998; Ashok et al. 2007). In the austral summer, the storm track is enhanced (suppressed) during El Niño (La Niña) because of the intensification of the STJ during El Niño (Bhaskaran and Mullan 2003; Ashok et al. 
(a) Fronts: EOF1, 16.6\%, DJF

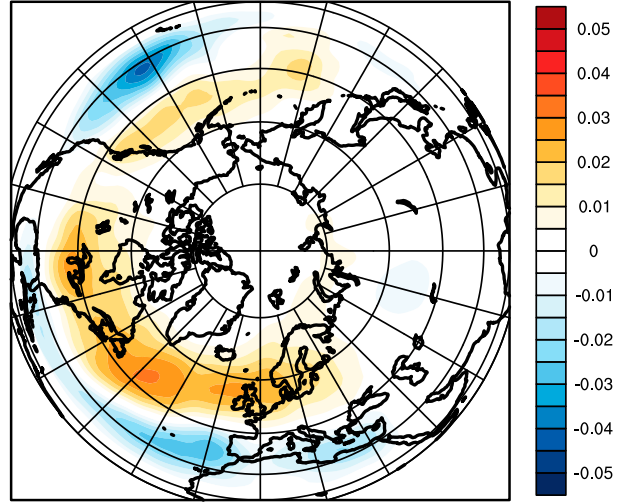

(c) Cyclones: EOF1, 11.6\%, DJF

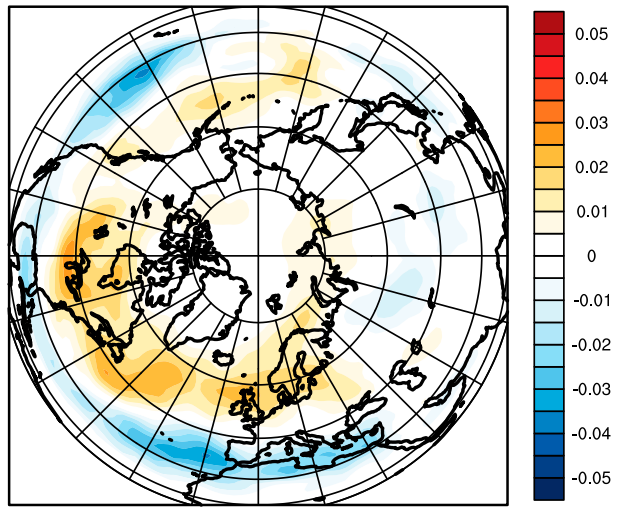

(e) PC 1, DJF

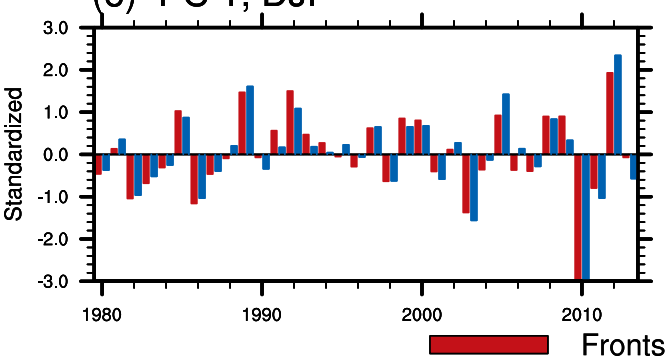

(b) Fronts: EOF1, 16.1\%, JJA

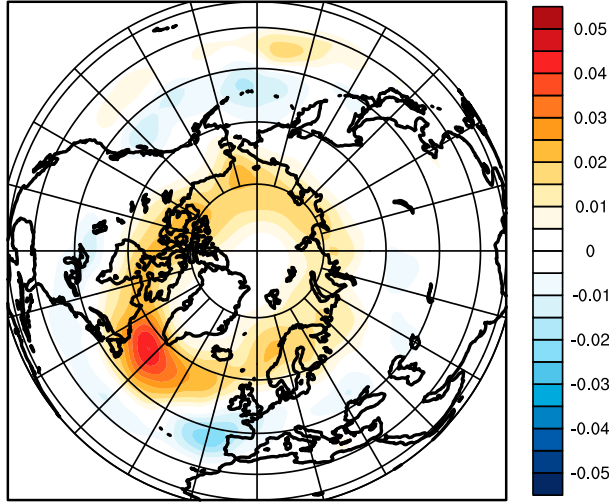

(d) Cyclones: EOF1, 14.2\%, JJA

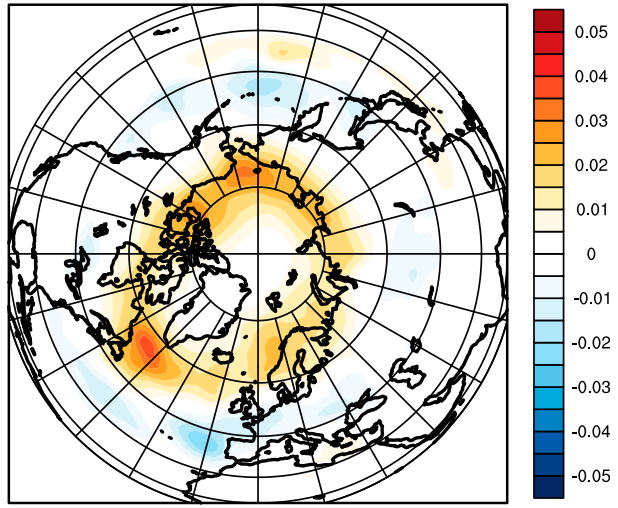

(f) PC 1, JJA

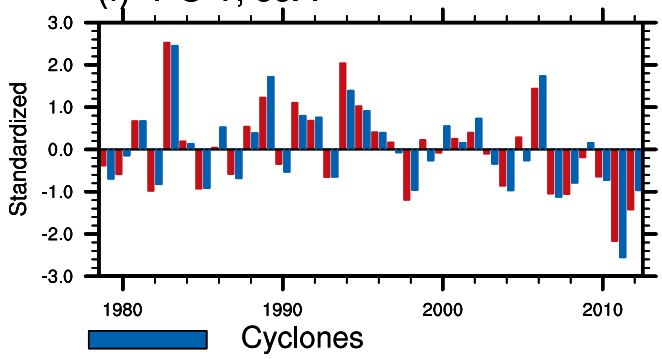

FIG. 9. (a) DJF and (b) JJA first EOFs of the frontal frequency in the NH. (c),(d) As in (a),(b), but for cyclone frequency. (e) DJF and (f) JJA normalized PCs associated with the first EOFs.

2007). Cai et al. (2011) found that anomalous convection associated with El Niño instigates a Rossby wave train in austral winter from the central equatorial Pacific poleward, which is known as the Pacific-South American pattern (Mo and Higgins 1998; Garreaud and Battisti 1999), and a second Rossby wave train emanating from equatorial Africa, with centers of opposite polarity westsouthwest and south of Australia, respectively. Pezza et al. (2008) demonstrated that when the Southern Oscillation index (a proxy for the ENSO) was positive there was an increase in cyclone frequencies in the Tasman Sea and in southeastern Australia and fewer cyclones around Antarctica and southern South America. Moreover, Yuan (2004) showed that there are changes in the Hadley cell, STJ, and the Rossby wave train associated with the ENSO that link the tropical forcing to highlatitude processes in the atmosphere and ocean.

Figure 8 shows the spatial distribution of the correlation between frontal frequency and the ENSO index. The warm ENSO phase is associated with a reduction in the number of fronts in the middle latitudes in the central and eastern South Pacific in all seasons, particularly in winter (JJA). In the western Pacific, frontal activity intensifies during El Niño, especially in summer (DJF). 
TABLE 1. Correlation coefficient between the PCs associated with the first and the second EOFs (PC1 and PC2, respectively) and the indices of atmospheric circulation. The last line shows the correlation between frontal and cyclone PCs (FvsC). Correlation coefficients significant at $99 \%$ are shown in bold, significant at $95 \%$ are shown in italics, and significant at $90 \%$ are shown in regular font.

\begin{tabular}{|c|c|c|c|c|c|c|}
\hline \multicolumn{7}{|c|}{$\mathrm{NH}$} \\
\hline & \multicolumn{4}{|c|}{$\mathrm{PC} 1$} & \multicolumn{2}{|c|}{$\mathrm{PC} 2$} \\
\hline & \multicolumn{2}{|c|}{ DJF } & \multicolumn{2}{|c|}{ JJA } & \multicolumn{2}{|c|}{ JJA } \\
\hline & Fronts* & Cyclones* & Fronts & Cyclones & Fronts* & Cyclones* \\
\hline NAO & 0.71 & 0.71 & 0.84 & 0.76 & 0.29 & 0.42 \\
\hline NAM & 0.62 & -0.58 & & & & \\
\hline PNA & 0.43 & 0.35 & & & & \\
\hline ENSO & -0.43 & -0.40 & & & -0.24 & -0.17 \\
\hline \multirow[t]{5}{*}{ FvsC } & \multicolumn{2}{|c|}{0.96} & \multicolumn{2}{|c|}{0.95} & & \\
\hline & \multicolumn{4}{|c|}{$\mathrm{SH}$} & & \\
\hline & \multicolumn{4}{|c|}{ PC1 } & \multicolumn{2}{|c|}{$\mathrm{PC} 2$} \\
\hline & \multicolumn{2}{|c|}{ DJF } & \multicolumn{2}{|c|}{ JJA } & \multicolumn{2}{|c|}{ JJA } \\
\hline & Fronts & Cyclones & Fronts* & Cyclones* & Fronts* & Cyclones* \\
\hline SAM & 0.86 & 0.84 & 0.03 & -0.02 & -0.67 & -0.08 \\
\hline ENSO & -0.49 & -0.35 & 0.47 & 0.44 & 0.32 & 0.32 \\
\hline FvsC & \multicolumn{2}{|c|}{0.95} & \multicolumn{2}{|c|}{0.88} & \multicolumn{2}{|c|}{0.62} \\
\hline
\end{tabular}

* Mode is not separated from nearby modes according to the North et al. (1982) test (applied at the 95\% confidence level).

The observed anomalies in the Pacific correspond well with the intensification in the STJ. The austral summer exhibits a strong relationship between ENSO and frontal activity also in other parts of the $\mathrm{SH}$, particularly in the Indian Ocean, where the correlations are strongly positive, and in the Southern Ocean, where they are strongly negative. In JJA, there is an intensification of frontal activity around the coast of West Antarctica during the warm ENSO phase. Cyclone frequencies demonstrate significant correlations with the ENSO only in summer (Fig. 8c), being positively correlated in the middle latitudes and negatively in the high latitudes of the $\mathrm{SH}$ and low latitudes of the western Pacific and eastern Indian Ocean. Cyclone correlations in the middle and high latitudes are in agreement with the frontal behavior in response to the ENSO with cyclone modes being shifted poleward. Frontal intensities demonstrate a relatively weak relationship with the ENSO, showing mainly negative correlations in the middle latitudes in both seasons.

In summary, the variability of frontal frequency in the $\mathrm{NH}$ is largely associated with the NAO, especially in a wide belt from the east coast of North America to Europe, in both winter and summer and ENSO in the Pacific-North American sector in DJF. In the SH the frontal behavior is strongly related to the SAM and ENSO. The associations of frontal variability with these large-scale modes is consistent with the cyclone response; however, the fronts demonstrate larger areas of significant correlations that are shifted equator ward compared to cyclones. Larger areas of significant correlation are partly explained by the difference in the mapping techniques as the estimates of fronts frequencies are based on all points along the frontal line, whereas the cyclones are represented by the central points only.

\section{c. EOF analysis of frontal frequency}

To complement our extensive examination of the variability of synoptic behavior we have conducted EOF analyses. The leading modes of frontal and cyclone variability (EOF1) in the NH are shown in Fig. 9. In DJF during the positive phase of EOF1, the number of fronts and cyclones between $40^{\circ}$ and $60^{\circ} \mathrm{N}$ in the Atlantic, North America, and the Pacific increases with a corresponding decrease around $30^{\circ}-40^{\circ} \mathrm{N}$ from the west $\mathrm{Pa}$ cific to the Mediterranean. We note here that the DJF mode is degenerate for the period used here because of the high sample error [we indicate with an asterisk in Table 1 the EOFs that fail the North et al. (1982) separation test at the $95 \%$ confidence level]. However, we make the point that it is highly correlated with the NAO and the NAM (both $r=0.71$ ), which suggests that this mode does have physical meaning, despite it being degenerate. On this basis, we are prepared to discuss the structure of such modes. In summer (Figs. 9b,d), the leading modes of frontal and cyclone variability have their maximum loadings to the south of Greenland and to the north of the coastline of the Arctic Ocean. It reflects high variability of summer synoptic activity in the polar regions of the $\mathrm{NH}$, which are known to be very 
sensitive to the climate change. Summer EOF1 is in close relationship to the NAO ( $r=0.84$ and 0.76 for fronts and cyclones, respectively). The leading EOFs for frontal and cyclone frequencies are highly correlated with each other ( $r=0.96$ in DJF and 0.95 in JJA). Interestingly, the main areas of frontal and cyclone variability, represented by EOF1, are located at the same latitudes, instead of being shifted in a north-south direction, as might be expected from the correlation analysis in the previous section (3b).

The second EOF (EOF2) in the NH is not robust for either winter or summer. However, following the rationale outlined above, we show here JJA EOF2 for both fronts and cyclones (Figs. 10a,b), as they reveal a very interesting structure in the Arctic. In particular, this mode, being very similar to the EOF1s in the Atlantic section, exhibits high negative loadings in the Chukchi Sea, the region to the south of the area where the greatest amount of sea ice is being lost. The EOF2 for cyclones is reasonably well associated with the NAO $(r=0.42)$; for the fronts, this relationship is weaker $(r=$ 0.29). Overall, even though EOF2 is degenerate, a tentative inference can be made that a positive NAO during summer enhances the synoptic activity over the Atlantic but at the same time reduces the number of fronts and cyclones in the Pacific sector of the Arctic.

In the $\mathrm{SH}$ the leading modes of the frontal and cyclone variability in DJF have an annular structure with anomalies of the opposite sign around $60^{\circ} \mathrm{S}$ and the belt between $30^{\circ}$ and $45^{\circ} \mathrm{S}$ (Figs. 11a,c). The correlation with the SAM index is 0.84 for the fronts and 0.86 for the cyclones. These modes are also correlated with the ENSO $(r=$ -0.49 and -0.35 , respectively). The (degenerate) winter EOF1 in the SH is closely associated with ENSO: the main center of action is located in the mid Pacific with loadings of the opposite sign in the northeast Indian Ocean and to the south of $60^{\circ} \mathrm{S}$ (Figs. $11 \mathrm{~b}, \mathrm{~d}$ ). The correlations with the ENSO are 0.47 and 0.44 for fronts and cyclones, respectively. The first modes of frontal and cyclone variability are closely related to each other in both seasons ( $r=0.95$ in DJF and 0.88 in JJA).

In winter, the SAM is revealed by the second EOF of frontal variability. This mode is represented by two centers of action in the midlatitudes of the Indian Ocean and the southeast Pacific and opposite signs located in the low latitudes of the west Pacific (Fig. 12a). Its correlation with the SAM is -0.67 . At the same time, EOF2 of JJA cyclone variability (Fig. 12b), being associated with EOF2 of frontal variability $(r=0.62)$, is not significantly correlated with the SAM $(r=-0.08)$.

The EOF analysis of the frontal and cyclone variability reveals that their leading modes are very similar in both seasons and are highly correlated with the main (a) Fronts: EOF2, $8.3 \%$, JJA

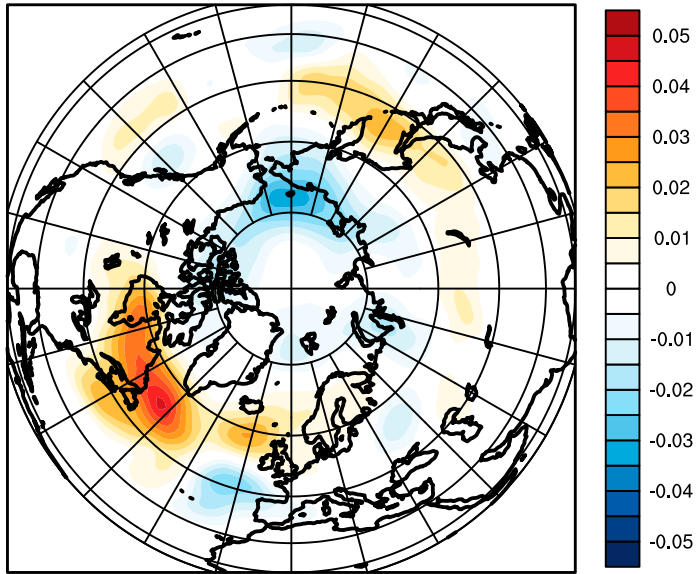

(b) Cyclones: EOF2, 7.7\%, JJA

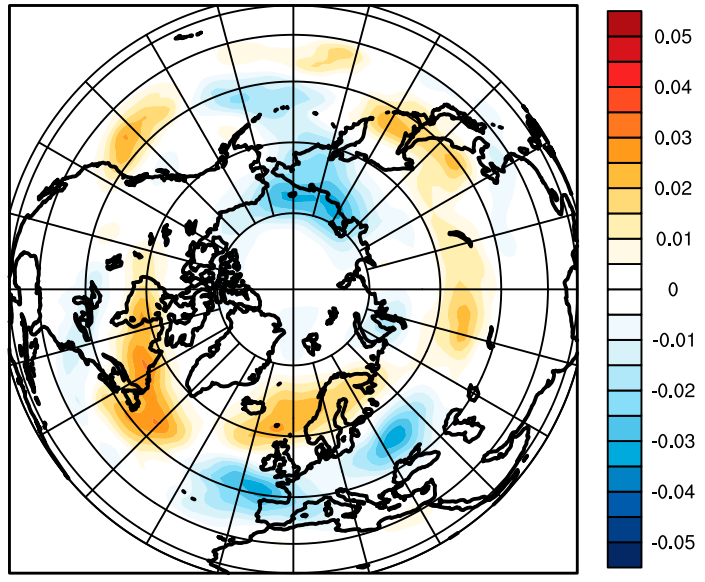

(c) PC 2, JJA

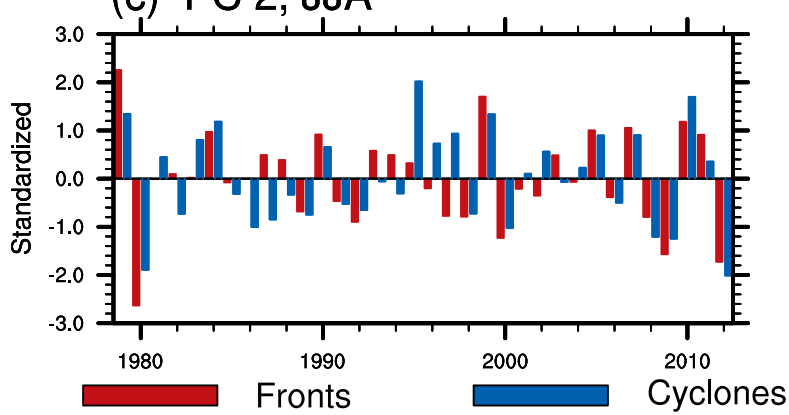

FIG. 10. JJA second EOFs of the (a) frontal and (b) cyclone frequency in the $\mathrm{NH}$ and (c) their associated PCs.

modes of the atmospheric circulation. It should be noted here that EOFs of fronts explain more of the variance than do those of cyclones. Taken together with the higher correlations between frontal frequencies and the large-scale modes of atmospheric variability, this points to the conclusion that fronts offer a more insightful perspective into synoptic behavior than do cyclones. 
(a) Fronts: EOF1, 17.4\%, DJF

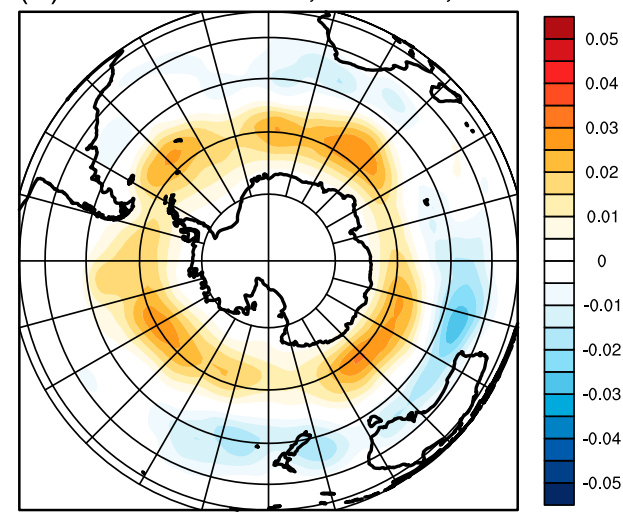

(c) Cyclones: EOF1, 14.0\%, DJF

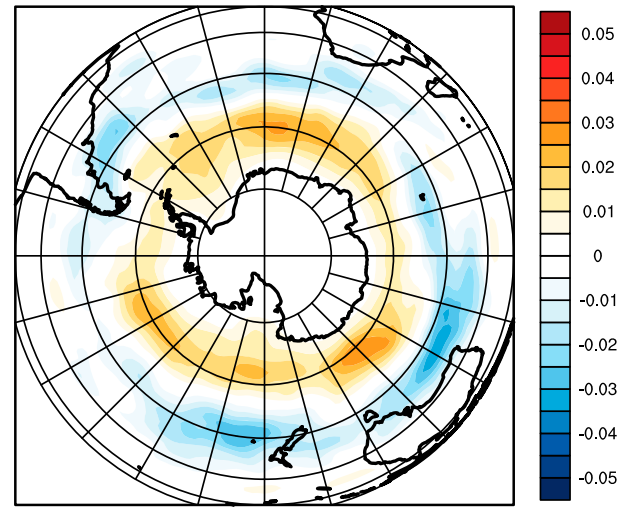

(e) PC 1, DJF

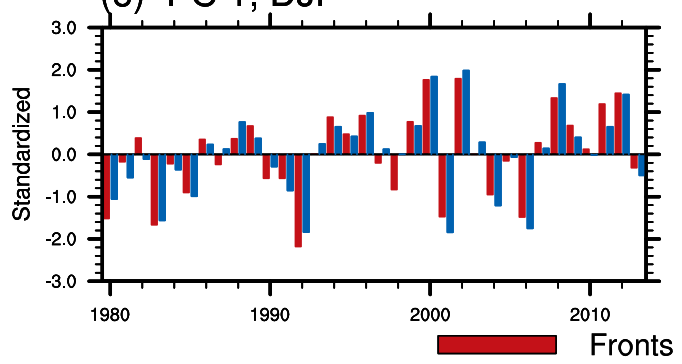

(b) Fronts: EOF1, 14.0\%, JJA

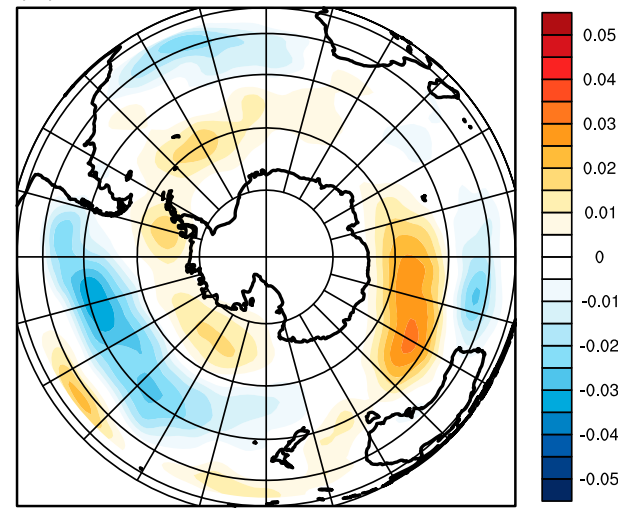

(d) Cyclones: EOF1, 10.1\%, JJA

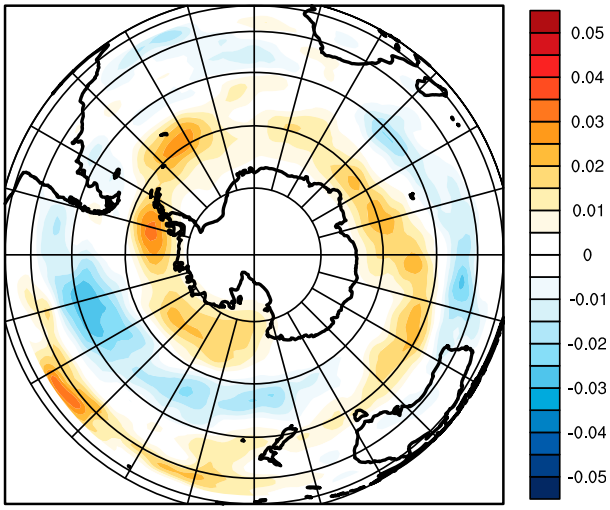

(f) PC 1, JJA

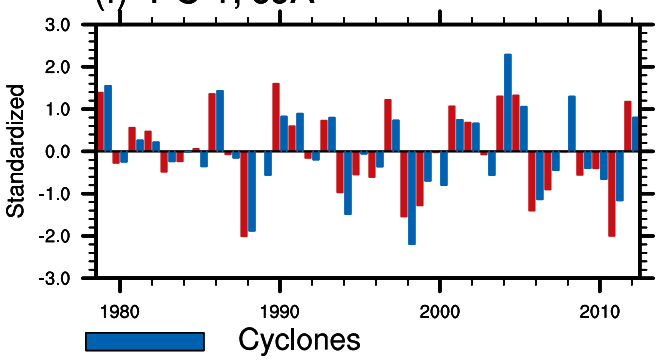

FIG. 11. As in Fig. 9, but for the SH.

\section{d. Frontal variability in key areas of the polar regions}

In Figs. 9 and 10, we have seen that the first two EOFs of summer synoptic variability show high loadings in the Arctic Ocean just to the north of the continental coastline that encloses it. This is the very region that has experienced significant sea ice reductions over the last few decades, and the question arises as to the possible connection between these two. For a number of reasons, polar regions are particularly sensitive to global warming (Miller et al. 2013) and in this final component of our global analysis we focus specifically on the changes in frontal behavior in the polar domains.
Figures 13a,b show the time series of the number of fronts per each month for our period of analysis and their anomalies from their respective monthly means in the Alaskan-Canadian sector of the Arctic $\left(70^{\circ}\right.$ $\left.90^{\circ} \mathrm{N}, 180^{\circ}-270^{\circ} \mathrm{E}\right)$. This area has been experiencing rapid summer sea ice reduction in recent years. It may be noticed that in the late 2000s there was a negative anomaly in the number of fronts in summer and early autumn. This is consistent with the analysis of Screen et al. (2011), who showed that fewer cyclones (and, by implication, fronts) in the central Arctic Ocean during May-July favor low sea ice area at the end of the melt season. Thus, in 2007 and 2011, when the Arctic sea ice 
(a) Fronts: EOF2, 11.8\%, JJA

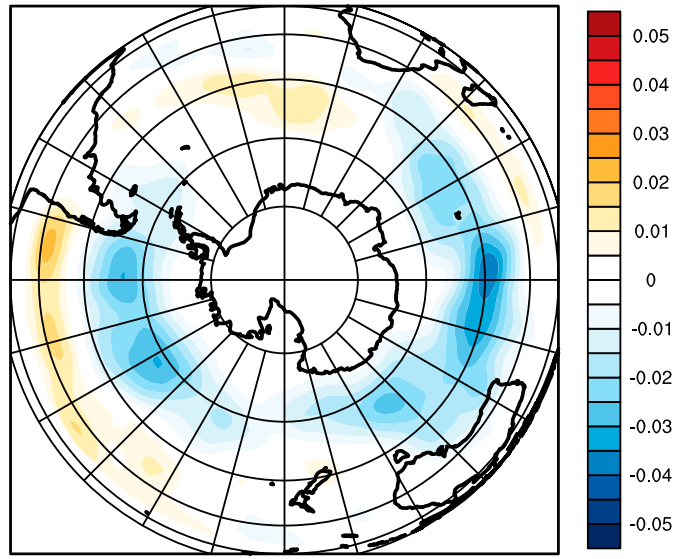

(b) Cyclones: EOF2, 7.8\%, JJA

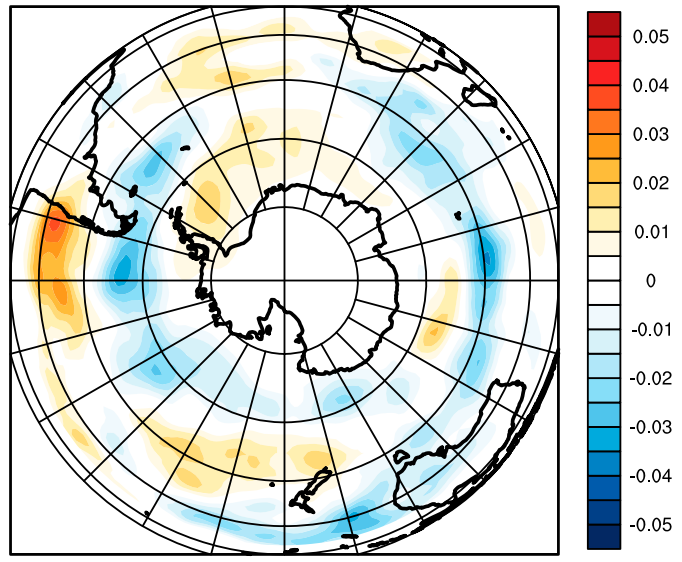

(c) PC 2, JJA

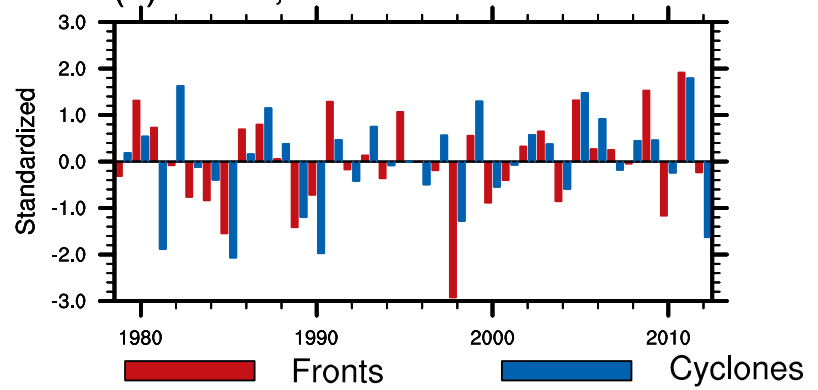

FIG. 12. As in Fig. 10, but for the SH.

extent reached its second and third lowest values, there was a reduction in frontal activity in warm period, particularly in August-September, with anomalies reaching $80 \%$. However, in 2012, when the record low Arctic sea ice extent was observed, the frontal activity remained low in spring but in summer months it reached its average level. This may seem to contradict with earlier statement that suppressed synoptic activity in summer months favors a reduction in the sea ice. However, the recent study by Kriegsmann and Brümmer (2014) revealed that the relationship between the sea ice and synoptic activity depends on various factors, including ice thickness, season, location, intensity, and size of the synoptic systems affecting the ice. They concluded that in summer the cyclone-induced reduction of sea ice concentration is the largest, particularly in areas with thinner ice. We infer here that the intensity of synoptic systems and their location are playing a larger role in determining the sea ice behavior than the actual number of those systems. Thus, sea ice reduction may occur even during years with reduced number of fronts or cyclones [as found by Screen et al. (2011)]. Moreover, as the sea ice becomes thinner (Zygmuntowska et al. 2014), it becomes more susceptible to the influence of storms and fronts and even small variations in synoptic activity may have a large effect (of both signs) on the sea ice.

Figures $13 \mathrm{c}$,d show analogous statistics for the Weddell Sea $\left(60^{\circ}-75^{\circ} \mathrm{S}, 300^{\circ}-350^{\circ} \mathrm{E}\right)$ in the Antarctic area. The relative variability is smaller in this region, with most changes occurring in the austral summer: in the late 1980s there is a decrease in summer frontal frequencies, which corresponds with El Niño events, while in late 2000s there has been an increase of summer frontal activity along with the prevalence of La Niña events. This illustrates the effect of the ENSO on high latitudes. Frontal variability in other regions of the $\mathrm{SH}$, including the Amundsen-Bellingshausen Sea region, which has shown a large reduction in the sea ice in recent times, was also analyzed (not shown) but in all regions the number of fronts shows relatively small interannual variation compared to the $\mathrm{NH}$.

\section{Concluding remarks}

The variability of global frontal activity has been analyzed here using ERA-Interim data starting from 1979. The algorithm applied for frontal identification is based on the meridional wind shift, which gives very robust results in identifying mobile fronts that are typically cold atmospheric fronts. Trends in frontal frequencies and leading modes of frontal variability were identified, as well as associations with cyclones and modes of atmospheric circulation in both the $\mathrm{NH}$ and $\mathrm{SH}$.

We show that in DJF there has been a poleward shift of frontal frequency in the North Pacific and an analogous poleward shift of frontal activity in the $\mathrm{SH}$, which is consistent with the seasonality of other synoptic trends in both hemispheres that show maxima during the boreal winter for the $\mathrm{NH}$ and the austral summer in the $\mathrm{SH}$. Another distinctive feature of frontal activity is 
(a) Number of fronts, the Arctic

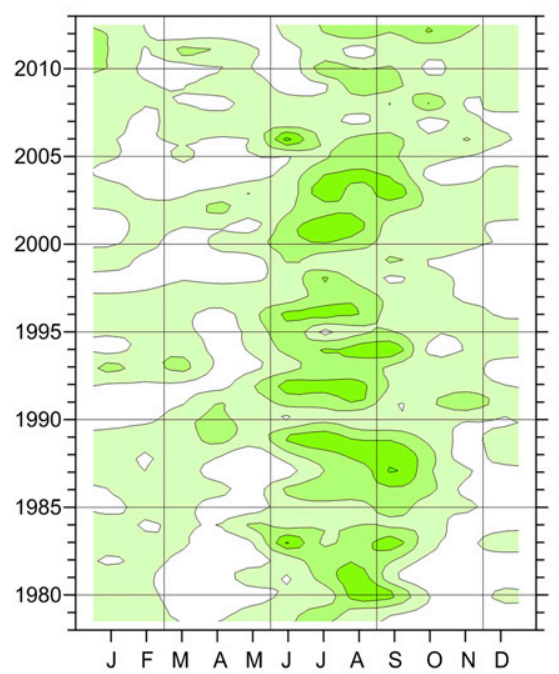

(c) Number of fronts, the Weddell Sea

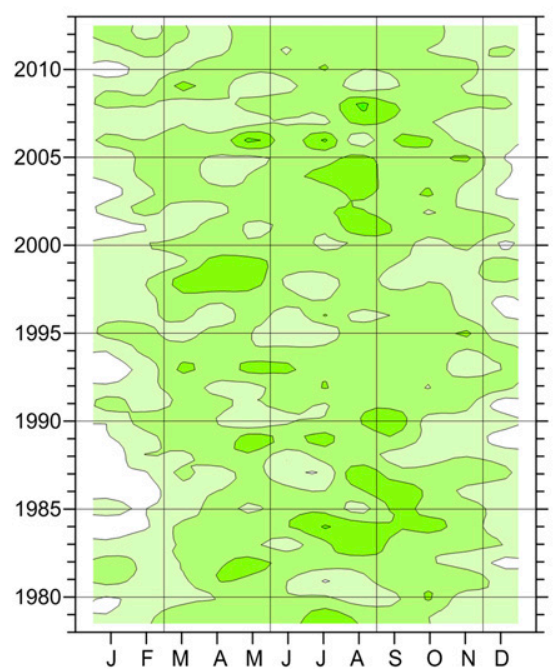

(b) anomalies, the Arctic
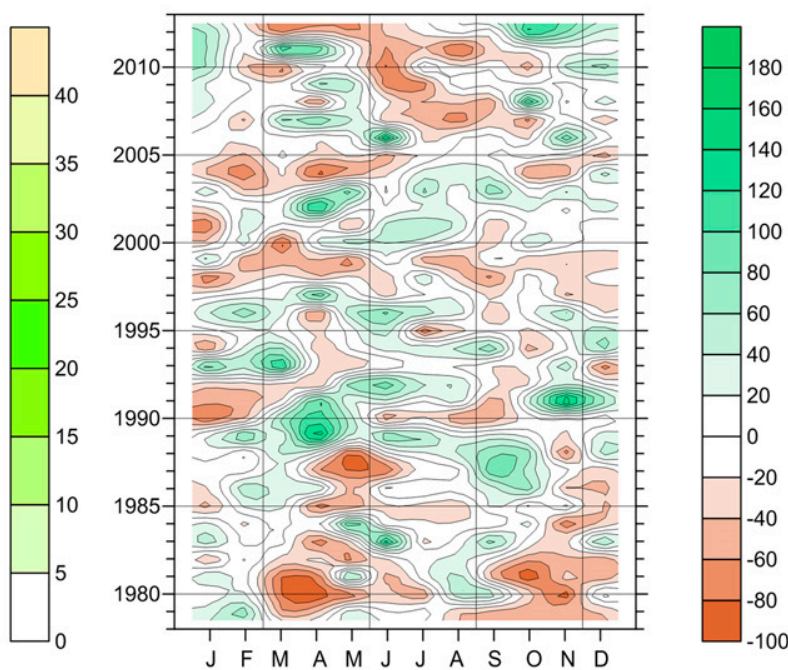

(d) anomalies, the Weddell Sea
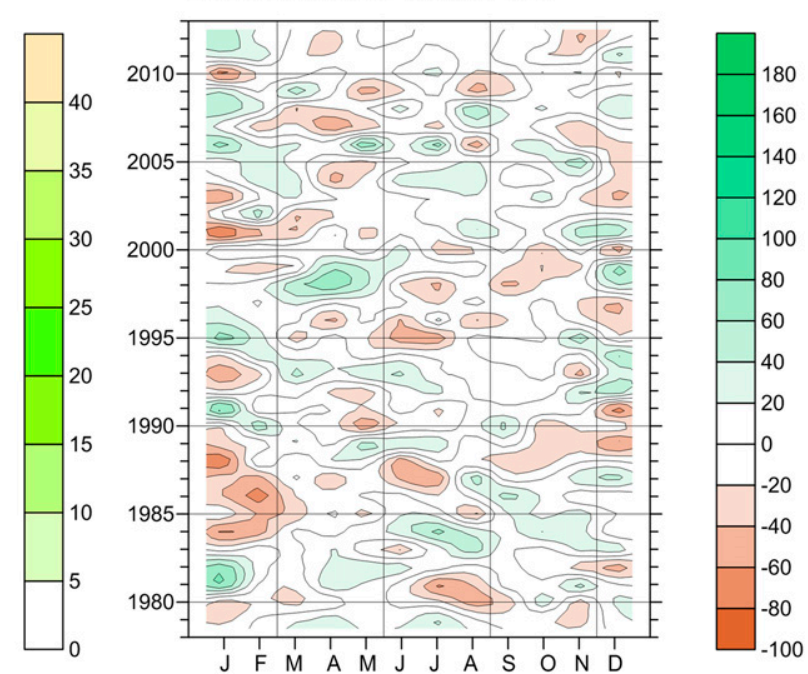

FIG. 13. Monthly averaged number of fronts in (a) the Arctic $\left(70^{\circ}-90^{\circ} \mathrm{N}, 180^{\circ}-270^{\circ} \mathrm{E}\right)$ and (c) the Weddell Sea $\left(60^{\circ}-75^{\circ} \mathrm{S}, 300^{\circ}-350^{\circ} \mathrm{E}\right)$ and $(\mathrm{b}),(\mathrm{d})$ their corresponding anomalies in percentages.

a reduction of the number of fronts over the CAA in the boreal summer, which may be linked to the rapid reduction in the summer Arctic sea ice during the last decades. It has been shown that the leading modes of interannual variability of frontal activity are highly correlated with the corresponding modes of cyclone frequency and are largely associated with the main modes of atmospheric variability, in particular with the NAO over large parts of the NH and the SAM and ENSO in the SH.

These findings resemble those for cyclone activity, which is not surprising, given that these synoptic systems are intimately related. However, we have identified some striking regional differences. In general, the climatological maxima of frontal activity are shifted equatorward compared to main areas of cyclone activity and that means that areas of the largest synoptic variability associated with fronts are also shifted toward the equator. One of the key reasons for conducting this research was the appreciation that fronts, by their elongated nature, influence a greater area than do their associated cyclones. As such, they play a larger net role in precipitation (e.g., Papritz et al. 2014), meridional heat, moisture and momentum transfers, etc., than do cyclones. Our analysis highlights the importance of quantifying frontal behavior when investigating the workings of the climate system. 
Acknowledgments. The authors thank Kevin Keay for his help in setting up the frontal identification scheme. We are grateful to two anonymous reviewers, whose insightful comments helped to improve the original manuscript. Parts of this research were made possible by a grant from the Australian Research Council.

\section{REFERENCES}

Archer, C. L., and K. Caldeira, 2008: Historical trends in the jet streams. Geophys. Res. Lett., 35, L08803, doi:10.1029/ 2008 GL033614.

Ashok K., H. Nakamura, and T. Yamagata, 2007: Impacts of ENSO and Indian Ocean dipole events on the Southern Hemisphere cyclone-track activity during austral winter. J. Climate, 20, 3147-3163, doi:10.1175/JCLI4155.1.

Berry, G., M. J. Reeder, and C. Jakob, 2011: A global climatology of atmospheric fronts. Geophys. Res. Lett., 38, L04809, doi:10.1029/ 2010GL046451.

Bhaskaran, B., and A. B. Mullan, 2003: El Niño-related variations in the southern Pacific atmospheric circulation: model versus observations. Climate Dyn., 20, 229-239, doi:10.1007/ s00382-002-0276-2.

Bromwich, D. H., J. P. Nicolas, and A. J. Monaghan, 2011: An assessment of precipitation changes over Antarctica and the Southern Ocean since 1989 in contemporary global reanalyses. J. Climate, 24, 4189-4209, doi:10.1175/2011JCLI4074.1.

Cai, W., P. van Rensch, T. Cowan, and H. H. Hendon, 2011: Teleconnection pathways of ENSO and the IOD and the mechanisms for impacts on Australian rainfall. J. Climate, 24, 39103923, doi:10.1175/2011JCLI4129.1.

Catto, J. L., and S. Pfahl, 2013: The importance of fronts for extreme precipitation. J. Geophys. Res., 118, 10 791-10 801, doi:10.1002/ jgrd.50852.

_ C. Jakob, G. Berry, and N. Nicholls, 2012: Relating global precipitation to atmospheric fronts. Geophys. Res. Lett., 39, L10805, doi:10.1029/2012GL051736.

Chen, G., and I. M. Held, 2007: Phase speed spectra and the recent poleward shift of Southern Hemisphere surface westerlies. Geophys. Res. Lett., 34, L21805, doi:10.1029/2007GL031200.

Climate Prediction Center, cited 2014: Typical impacts of warm (El Niño/Southern Oscillation-ENSO) and cold episodes. [Available online at http://www.cpc.noaa.gov/products/analysis_monitoring/ impacts/enso.html.]

Cohen, J., and M. Barlow, 2005: The NAO, the AO, and global warming: How closely related? J. Climate, 18, 4498-4513, doi:10.1175/JCLI3530.1.

Comiso, J. C., 2003: Warming trends in the Arctic from clear sky satellite observations. J. Climate, 16, 3498-3510, doi:10.1175/ 1520-0442(2003)016<3498:WTITAF $>2.0$. CO;2.

Dee, D. P., and Coauthors, 2011: The ERA-Interim reanalysis: Configuration and performance of the data assimilation system. Quart. J. Roy. Meteor. Soc., 137, 553-597, doi:10.1002/qj.828.

Deser, C., J. E. Walsh, and M. S. Timlin, 2000: Arctic sea ice variability in the context of recent atmospheric circulation trends. J. Climate, 13, 617-633, doi:10.1175/1520-0442(2000)013<0617: ASIVIT $>2.0 . \mathrm{CO} ; 2$.

, M. A. Alexander, and M. S. Timlin, 2003: Understanding the persistence of sea surface temperature anomalies in midlatitudes. J. Climate, 16, 57-72, doi:10.1175/1520-0442(2003)016<0057: UTPOSS $>2.0 . \mathrm{CO} ; 2$.
Garreaud, R. D., and D. S. Battisti, 1999: Interannual (ENSO) and interdecadal (ENSO-like) variability in the Southern Hemisphere tropospheric circulation. J. Climate, 12, 2113-2123, doi:10.1175/ 1520-0442(1999)012<2113:IEAIEL >2.0.CO;2.

Gong, D., and S. Wang, 1999: Definition of Antarctic Oscillation index. Geophys. Res. Lett., 26, 459-462, doi:10.1029/ 1999GL900003.

Hakkinen, S., A. Proshutinsky, and I. Ashik, 2008: Sea ice drift in the Arctic since the 1950s. Geophys. Res. Lett., 35, L19704, doi:10.1029/2008GL034791.

Halpert, M. S., and C. F. Ropelewski, 1992: Surface temperature patterns associated with the Southern Oscillation. J. Climate, 5, 577-593, doi:10.1175/1520-0442(1992)005<0577: STPAWT $>2.0 . \mathrm{CO} ; 2$.

Hodges, K. I., R. W. Lee, and L. Bengtsson, 2011: A comparison of extratropical cyclones in recent reanalyses ERA-Interim, NASA MERRA, NCEP CFSR, and JRA-25. J. Climate, 24, 4888-4906, doi:10.1175/2011JCLI4097.1.

Hope, P., and Coauthors, 2014: A comparison of automated methods of front recognition for climate studies: A case study in southwest Western Australia. Mon. Wea. Rev., 142, 343363, doi:10.1175/MWR-D-12-00252.1.

Hurrell, J. W., 1995: Decadal trends in the North Atlantic Oscillation: Regional temperatures and precipitation. Science, 269, 676-679, doi:10.1126/science.269.5224.676.

— , and C. Deser, 2009: North Atlantic climate variability: The role of the North Atlantic Oscillation. J. Mar. Syst., 78, 28-41, doi:10.1016/j.jmarsys.2008.11.026.

Kriegsmann, A., and B. Brümmer, 2014: Cyclone impact on sea ice in the central Arctic Ocean: a statistical study. Cryosphere, 8, 303-317, doi:10.5194/tc-8-303-2014.

Lim, E.-P., and I. Simmonds, 2007: Southern Hemisphere winter extratropical cyclone characteristics and vertical organization observed with the ERA-40 reanalysis data in 1979-2001. J. Climate, 20, 2675-2690, doi:10.1175/JCLI4135.1.

Livezey, R. E., and W. Y. Chen, 1983: Statistical field significance and its determination by Monte Carlo techniques. Mon. Wea. Rev., 111, 46-59, doi:10.1175/1520-0493(1983)111<0046: SFSAID $>2.0 . \mathrm{CO} ; 2$.

Meneghini, B., I. Simmonds, and I. N. Smith, 2007: Association between Australian rainfall and the southern annular mode. Int. J. Climatol., 27, 109-121, doi:10.1002/joc.1370.

Miller, G. H., S. J. Lehman, K. A. Refsnider, J. R. Southon, and Y. Zhong, 2013: Unprecedented recent summer warmth in Arctic Canada. Geophys. Res. Lett., 40, 5745-5751, doi:10.1002/ 2013GL057188.

Mo, K. C., and R. W. Higgins, 1998: The Pacific-South American modes and the tropical intraseasonal oscillation. Mon. Wea. Rev., 126, 1581-1596, doi:10.1175/1520-0493(1998)126<1581: TPSAMA $>2.0 . \mathrm{CO} ; 2$.

Neu, U., and Coauthors, 2013: IMILAST: A community effort to intercompare extratropical cyclone detection and tracking algorithms. Bull. Amer. Meteor. Soc., 94, 529-547, doi:10.1175/ BAMS-D-11-00154.1.

Nicolas, J. P., and D. H. Bromwich, 2011: Precipitation changes in high southern latitudes from global reanalyses: A cautionary tale. Surv. Geophys., 32, 475-494, doi:10.1007/s10712-011-9114-6.

North, G. R., T. L. Bell, R. F. Cahalan, and F. J. Moeng, 1982: Sampling errors in the estimation of empirical orthogonal functions. Mon. Wea. Rev., 110, 699-706, doi:10.1175/ 1520-0493(1982)110<0699:SEITEO > 2.0.CO;2.

Papritz, L., S. Pfahl, I. Rudeva, I. Simmonds, H. Sodemann, and H. Wernli, 2014: The role of extratropical cyclones and fronts 
for Southern Ocean freshwater fluxes. J. Climate, 27, 62056224, doi:10.1175/JCLI-D-13-00409.1.

Pezza, A. B., I. Simmonds, and J. A. Renwick, 2007: Southern Hemisphere cyclones and anticyclones: Recent trends and links with decadal variability in the Pacific Ocean. Int. J. Climatol., 27, 1403-1419, doi:10.1002/joc.1477.

, T. Durrant, I. Simmonds, and I. Smith, 2008: Southern Hemisphere synoptic behavior in extreme phases of SAM, ENSO, sea ice extent, and southern Australia rainfall. J. Climate, 21, 55665584, doi:10.1175/2008JCLI2128.1.

Pinto, J. G., T. Spangehl, U. Ulbrich, and P. Speth, 2005: Sensitivities of a cyclone detection and tracking algorithm: Individual tracks and climatology. Meteor. Z., 14, 823-838, doi:10.1127/ 0941-2948/2005/0068.

Raible, C. C., P. M. Della-Marta, C. Schwierz, H. Wernli, and R. Blender, 2008: Northern Hemisphere extratropical cyclones: A comparison of detection and tracking methods and different reanalyses. Mon. Wea. Rev., 136, 880-897, doi:10.1175/ 2007MWR2143.1.

Renard, R. J., and L. C. Clarke, 1965: Experiments in numerical objective frontal analysis. Mon. Wea. Rev., 93, 547-556, doi:10.1175/1520-0493(1965)093<0547:EINOFA > 2.3.CO;2.

Schemm, S., I. Rudeva, and I. Simmonds, 2015: Extratropical fronts in the lower troposphere-Global perspectives obtained from two automated methods. Quart. J. Roy. Meteor. Soc., doi: 10.1002/ qj.2471, in press.

Screen, J. A., I. Simmonds, and K. Keay, 2011: Dramatic interannual changes of perennial Arctic sea ice linked to abnormal summer storm activity. J. Geophys. Res., 116, D15105, doi:10.1029/2011JD015847.

Simmonds, I., 2015: Comparing and contrasting the behaviour of Arctic and Antarctic sea ice over the 35-year period 19792013. Ann. Glaciol., 56, 18-28, doi:10.3189/2015AoG69A909.

_ , and K. Keay, 2002: Surface fluxes of momentum and mechanical energy over the North Pacific and North Atlantic Oceans. Meteor. Atmos. Phys., 80, 1-18, doi:10.1007/s007030200009.

_- and J. C. King, 2004: Global and hemispheric climate variations affecting the Southern Ocean. Antarct. Sci., 16, 401-413, doi:10.1017/S0954102004002226.

_- and K. Keay, 2009: Extraordinary September Arctic sea ice reductions and their relationships with storm behavior over
1979-2008. Geophys. Res. Lett., 36, L19715, doi:10.1029/ 2009GL039810.

_ C. Burke, and K. Keay, 2008: Arctic climate change as manifest in cyclone behavior. J. Climate, 21, 5777-5796, doi:10.1175/ 2008JCLI2366.1.

_ of Southern Hemisphere mobile fronts in a modern reanalysis. J. Climate, 25, 1945-1962, doi:10.1175/JCLI-D-11-00100.1.

Solman, S. A., and I. Orlanski, 2014: Poleward shift and change of frontal activity in the Southern Hemisphere over the last 40 years. J. Atmos. Sci., 71, 539-552, doi:10.1175/ JAS-D-13-0105.1.

Thompson, D. W. J., and J. M. Wallace, 1998: The Arctic Oscillation signature in wintertime geopotential height and temperature fields. Geophys. Res. Lett., 25, 1297-1300, doi:10.1029/ 98GL00950.

_ , and S. Solomon, 2002: Interpretation of recent Southern Hemisphere climate change. Science, 296, 895-899, doi:10.1126/ science. 1069270 .

_ J. M. Wallace, and G. C. Hegerl, 2000: Annular modes in the extratropical circulation. Part II: Trends. J. Climate, 13, 1018-1036, doi:10.1175/1520-0442(2000)013<1018:AMITEC>2.0.CO;2.

Tilinina, N., S. K. Gulev, I. Rudeva, and P. Koltermann, 2013: Comparing cyclone life cycle characteristics and their interannual variability in different reanalyses. J. Climate, 26, 6419-6438, doi:10.1175/JCLI-D-12-00777.1.

Trenberth, K. E., and J. W. Hurrell, 1994: Decadal atmosphereocean variations in the Pacific. Climate Dyn., 9, 303-319, doi:10.1007/BF00204745.

- G. W. Branstator, D. J. Karoly, A. Kumar, N.-C. Lau, and C. Ropelewski, 1998: Progress during TOGA in understanding and modeling global teleconnections associated with tropical sea surface temperatures. J. Geophys. Res., 103, 14291-14324, doi:10.1029/97JC01444.

Yuan, X., 2004: ENSO-related impacts on Antarctic sea ice: A synthesis of phenomenon and mechanisms. Antarct. Sci., 16, 415-425, doi:10.1017/S0954102004002238.

Zygmuntowska, M., P. Rampal, N. Ivanova, and L. H. Smedsrud, 2014: Uncertainties in Arctic sea ice thickness and volume: New estimates and implications for trends. Cryosphere, 8, 705720, doi:10.5194/tc-8-705-2014. 